NBER WORKING PAPER SERIES

\title{
AN EXPLORATION OF THE INTERNATIONAL COMPARISON PROGRAM'S NEW GLOBAL ECONOMIC LANDSCAPE
}

\author{
Martin Ravallion \\ Working Paper 20338 \\ http://www.nber.org/papers/w20338
NATIONAL BUREAU OF ECONOMIC RESEARCH
1050 Massachusetts Avenue
Cambridge, MA 02138
July 2014

For their comments on an earlier version of this paper, the author is grateful to Shaohua Chen, Angus Deaton, Yuri Dikhanov, Dean Joliffe, Peter Lanjouw, Aaditya Mattoo, Stephen O'Connell, Luis Serven, staff of the International Comparison Program's Global Office and the ICP Results Review Group, and seminar participants at the World Bank. The author worked for the World Bank at the time the 2011 ICP was designed and implemented but was not involved in any decisions regarding that ICP round or any other round. The author has only had access to the publicly-released ICP data. The author received no financial support from the World Bank in preparing this paper. The views expressed herein are those of the author and do not necessarily reflect the views of the National Bureau of Economic Research.

NBER working papers are circulated for discussion and comment purposes. They have not been peerreviewed or been subject to the review by the NBER Board of Directors that accompanies official NBER publications.

(C) 2014 by Martin Ravallion. All rights reserved. Short sections of text, not to exceed two paragraphs, may be quoted without explicit permission provided that full credit, including $\odot$ notice, is given to the source. 
An Exploration of the International Comparison Program's New Global Economic Landscape Martin Ravallion

NBER Working Paper No. 20338

July 2014

JEL No. E31,I32,O47

\begin{abstract}
$\underline{\text { ABSTRACT }}$
The Purchasing Power Parity (PPP) rates from the 2011 round of the International Comparison Program (ICP) imply some dramatic revisions to price levels and real incomes across the world. The paper tries to understand these changes. Domestic inflation rates account for a share of the PPP changes, although less so for the 2011 revisions than prior ICP rounds. A marked downward drift in ICP price levels for developing countries also emerged in 2011. Conditional on domestic price changes, the co-movement of PPPs with market exchange rates suggests that that the ICP puts higher weight on more internationally comparable traded-goods than do domestic indices. There is also evidence of a Dynamic Penn Effect, whereby economic growth comes with higher prices. The drift is concentrated in the Asia regional groupings used for ICP implementation. The results are not consistent with expectations based on the only methodological change identified to date although other explanations remain to be investigated.
\end{abstract}

Martin Ravallion

Center for Economic Research

Georgetown University

ICC 580

Washington, DC 20057

and NBER

mr1185@georgetown.edu 
"How on earth do we explain these changes to counterparts, activists, students, and all those in the development community who have been using these numbers?" (Senior World Bank staff member writing to the author soon after the release of the 2011 ICP results.)

\section{Introduction}

It is well understood that international comparisons of GDP at market exchange rates are deceptive about real income disparities. The main reason is that some commodities are not internationally traded, thus removing the economic mechanism for attaining price parity across borders. The expectation is that poorer countries will have lower wage rates and (hence) lower prices of non-traded goods relative to traded ones. Thus the purchasing power parity (PPP) exchange rate differs systematically from the nominal exchange rate. The most common economic rationale is the classic Balassa-Samuelson model of a competitive market economy with mobile factors of production between the traded and non-traded-goods sectors. ${ }^{2}$

Motivated by this argument, the International Comparison Program (ICP) collects the primary price data across countries on which the ICP's PPP exchange rates are based. ${ }^{3}$ The easiest way to think about PPPs is to use the price-level index (PLI) given by the ratio of the PPP exchange rate to the ordinary market (or official) exchange rate (MER). You can think of the PLI as a measure of how cheaply one can live in a country with the \$US. The inverse of the PLI is a measure of the real exchange rate- the MER deflated by the PPP rate. This can also be thought of as the extent of the upward adjustment to GDP in switching from the MER to PPP. ${ }^{4}$

The PPP estimates from the 2011 ICP were released in April 2014 (World Bank, 2014). The results immediately attracted much attention since many developing countries saw substantial changes to their real incomes. The new global economic landscape suggests less inequality between the rich world and poor world, and far less poverty judged relative to a poverty line with constant US purchasing power; by one estimate the new PPPs imply almost half the global poverty rate for 2011 as the old PPPs. ${ }^{5}$

\footnotetext{
2 This was outlined independently by Balassa (1964) and Samuelson (1964). Ravallion (2013a) discusses possible concerns about the relevance of this model to developing countries. An alternative explanation was proposed by Bhagwati (1984) based on factor endowments, leading (labor-intensive) services to be cheaper in poor countries. ${ }^{3}$ The ICP is also the source of price data used for the Penn World Tables. An alternative to ICP price data is the World Cost of Living Survey by the Economist Intelligence Unit (2014). Unlike the ICP the micro-data on prices is available (at a price); for an application see Crucini and Yilmazkuday (2014).

${ }^{4}$ Note that the PLI is the ratio of GDP at MER to GDP at PPP.

${ }^{5}$ This is shown in Dykstra et al. (2014); also see Chandy and Kharas (2014) using a higher international line. A debate followed regarding the methods used by Dykstra et al.; see the comments on their blog post.
} 
PLIs have been on a rising trend. Between the 2005 and 2011 rounds of the ICP the mean across countries in the proportionate change in the PLI for GDP was $1.33 \%$ per annum (with a standard error of 0.22\%). The mean rate of change was almost identical between 1993 and 2005 rounds (1.35\% per annum, with a standard error of $0.22 \%$ per annum). The distributions around these means are also similar (Figure 1). However, these aggregates hide a huge dispersion at each new round and negligible correlation across time, both of which are evident in Figure 2, which plots the country-level annualized changes in the log PLI between 2005 and 2011 (vertical axis) against those between 1993 and 2005 (horizontal axis).

The ICP price data are collected in a decentralized way by country statistics offices under supervision from ICP regional offices. (For example, the Asian Development Bank in Manila runs the ICP for all of Asia, including South Asia.) The linkage method across regions is run by the global office (housed in the World Bank); this moves the PPP distributions of entire regions, keeping relativities fixed within regions. Given the importance of the ICP regional groupings to the implementation of the ICP it is of interest to also summarize the changes in PLIs at that level across the last three ICP rounds. Table 1 gives the annualized differences in the log PLI by ICP region. There are a number of significant regional effects but with little clear pattern. Asia’s PLI rose over 1993-2005 then stabilized on average.

One factor in rising PLIs is that growing developing economies can be expected to have rising real wage rates, at least beyond some "Lewis turning point."6 The PLI has long been known to have a positive income gradient across countries-giving what is known as the "Penn Effect". ${ }^{7}$ This is arguably the international community's main motivation for supporting the ICP in collecting its price data. Otherwise, we will tend to under-state living standards in developing countries. We can also expect to see the PPP rate rising relative to the market exchange rate with sustained growth in developing economies - indeed, it would surely be odd if it did not. This “Dynamic Penn Effect” (DPE) has been found to be a quite strong and stable feature of the changes in PPPs between the ICP rounds for 2005, 1993 and 1985 (Ravallion, 2013a). The fact that the PLI for Asia has not risen over 2005-11 (Table 1) is thus surprising given that there was so much growth in that region.

\footnotetext{
${ }^{6}$ This refers to the famous development model of Lewis (1954), which postulated that poor countries had a large rural labor surplus and that real wages would only start to rise with development once that surplus was absorbed.

7 The term "Penn effect" stems from the Penn World Tables (Summers and Heston, 1991), which provided the data that were used to establish this effect empirically. For evidence on the cross-sectional Penn Effect see Summers and Heston (1991), Rogoff (1996), Deaton and Heston (2010) and Crucini and Yilmazkuday (2014).
} 
This paper tries to better understand the changes in PPPs. The DPE is evident in the new PPPs, consistent with past ICP rounds. To help explaining the changes, the paper also formulates a new hypothesis, that there is an implicit preference for more internationally comparable traded goods in the ICP. The idea is simple. In constructing a CPI one wants to use goods typical of the country in question, while for a PPP one wants to use goods that are consumed in all countries and are reasonably commonly consumed. As a result, the goods lists used by the ICP tend to be quite different to those used by the CPIs. Again, these differences could be sizable between rich and poor countries. Given that the ICP is an international price survey, it can be expected that it will tend to give priority to internationally traded goods (which are more easily compared across countries) than do typical domestic consumption bundles, especially in poor countries. This can be called the hypothesis of Traded-Goods Preference (TGP). TGP is clearly a concern, given that the rationale of PPPs is to allow for differences in the prices of non-traded goods. The paper shows that the evidence on the role played by MERs in influencing PPP changes at given domestic inflation rates is consistent with TGP. This helps explain the PPP changes.

However, there is also evidence of an unexplained downward drift in the new price levels for many countries relative to their growth rates and also after allowing for the TGP. The drift is especially strong for Asia (East, South and West Asia) though it is not evident for China. One clue for further research lies in that fact that the "Asia drift" is very much associated with the geographic structure of ICP implementation.

\section{PPP revisions and domestic inflation rates}

The relationship between "PPP inflation" and “CPI inflation” is of interest from two perspectives. First, ICP users have almost invariably made their PPP conversions at one date (typically the ICP base date) and then used country-specific deflators over time. The longstanding view has been that consistency with national prices trumps international prices, as argued by Nuxoll (1994), amongst others. The large literature on growth empirics using Penn World Tables has followed this approach. This is also the practice used in the World Bank's global poverty monitoring (see, for example, Chen and Ravallion, 2010a). However, this practice is not beyond question. Inter-temporal comparisons using national deflators may cease to be consistent with international prices, as discussed in Johnson et al. (2013). Inconsistencies 
between PPP inflation rates and CPI rates will also entail that the choice of base year will matter to both growth empirics and calculations of global poverty and inequality measures.

Second, the near-universal practice in measuring the extent of the revisions at each ICP round is to compare the newly-reported PPP to an "extrapolated" PPP based solely on how a domestic deflator such as the Consumer Price Index (CPI) moved between ICP rounds (relative to the U.S.). This is how the World Development Indicators (WDI) updates PPPs between ICP rounds (as in, for example, World Bank, 2013). However, this practice does not seem to have an especially good record and it has been argued that the method can be improved by allowing for the DPE, which is sufficiently stable over time to allow more accurate extrapolations (Ravallion, 2013a).

Turning to the data, one finds a strong and significant correlation between PPP inflation and CPI inflation between the 1993 and 2005 rounds; the regression coefficient for PPP inflation on CPI inflation is 0.905 , with a White standard error of 0.032 . The $\mathrm{R}^{2}$ was 0.91 . Figure 4(a) gives the graph. However, this changed noticeably with the 2011 ICP, as can be seen in Figure 4(b) ${ }^{8}$ The unexplained variance is much higher than for the prior rounds; the $\mathrm{R}^{2}$ fell to 0.49 . The regression coefficient falls to 0.750 (s.e. $=0.072$ ). ${ }^{9}$ It might be conjectured that a stronger relationship is found for the consumption PPP, but this is not the case. The corresponding regression coefficient actually falls, to 0.654 (s.e. $=0.083$ ). ${ }^{10}$

It might be conjectured that there is an attenuation bias in the regression coefficient on CPI inflation due to (classical) measurement errors in the latter. Deaton and Aten point to the widespread use of the Laspeyres formula for CPIs, which does not allow for substitution possibilities when relative prices change. Errors can also come from the prices themselves. My understanding is that the PPPs were generally collected by the same units within government that collect the CPI price data, so one would expect the measurement errors in prices to be positively correlated, working against the attenuation bias. The net effect is ambiguous. Nonetheless, measurement errors in the CPI must be a concern. Deaton and Aten (2014) argue that switching to the implicit deflator in the national accounts may help reduce the effects of measurement error

\footnotetext{
${ }^{8}$ This drops four outliers (with unusually large reductions in the PPPs in 2011).

${ }^{9}$ When relevant, all standard errors reported in this paper are White heteroskedasticity-consistent.

${ }^{10}$ The difference in the interval of time between ICP rounds (six years for the 2000, versus 12 for 2005) may well be a factor; on the presumption that taking an average over a longer period would give greater precision, this may help explain the lower variance for the earlier period.
} 
in the CPI inflation rates. ${ }^{11}$ The regression coefficient of PPP inflation on the annualized rate of change in the GDP deflator is noticeably higher at 0.866 (s.e.=0.194). However, the unexplained variance rises markedly, with $\mathrm{R}^{2}=0.108$.

To explore this issue further, consider the following regression:

$$
\Delta_{t} \ln P P P_{i t}=\delta_{t}\left(1-U S_{i}\right)+\alpha_{1 t} \Delta_{t} \ln \left(D E F_{i t} / D E F_{t}^{U S}\right)+\varepsilon_{i t}
$$

The " $\Delta_{t}$ ” is the annualized change relative to the prior ICP round, $\tau_{t}$ years earlier; thus $\Delta_{t} x \equiv \Delta x_{t} / \tau_{t} . P P P_{i t}$ and $D E F_{i t}$ are the PPP and domestic deflator (respectively) for country $i$ in ICP round for date $t$. US $i$ is a dummy variable taking the value unity for the United States and $D E F_{i t}^{U S}$ is the U.S. deflator. The parameter $\delta_{t}$ gives the "PPP drift" relative to domestic price inflation.

Two observations can be made about Equation (1). First, the model is constrained to assure that the predicted change in the PPP is zero for the U.S., noting that PPP $=1$ for the U.S. (by construction) in all rounds. (In all regressions reported below the data are transformed such that the predicted value of the PPP or PLI for the U.S. is fixed over time.) Second, the relationship is allowed to change between ICP rounds, reflecting both methodological revisions and real effects.

Controlling for CPI inflation, the estimated drift in the new PPPs is $\hat{\delta}=-3.610 \%$ per annum with s.e.=1.428\%. ${ }^{12}$ On separating Europe and the (non U.S.) OECD from the rest it is clear that this drift is not just found for the developing countries; indeed, the drift is larger for Europe/OECD; using CPIs the drift is $-4.543 \%$ per annum (s.e.=2.566) as compared to -2.579 (0.616) for all other countries. ${ }^{13}$ By contrast, PPPs had a positive drift relative to inflation rates over 1993-2005. The estimated drift in the 2005 ICP round is $\hat{\delta}=2.073 \%$ (s.e. $=0.318$ ) per annum. However, this positive drift was solely for the developing world (all countries except Europe/OECD); for this group the drift in the earlier rounds was 3.071\% per annum (s.e.=0.422), as compared to $0.554 \%$ (0.325) for Europe/OECD (excluding the U.S).

\footnotetext{
${ }^{11}$ The DA argument rests on the fact that the implicit deflator obtained by dividing the current price aggregate in the national accounts by the corresponding constant price aggregate is a currently weighted Paasche index, as distinct from the more widely used Laspeyres formula used for CPIs.

${ }^{12}$ Using the GDP deflator instead one obtains $\hat{\delta}=-4.520 \%$ per annum with s.e. $=1.663 \%$.

${ }^{13}$ Using GDP deflators instead, the corresponding drifts are -5.125 (2.656) and -3.752 (0.774).
} 
So for the developing world, we can understand why the ICP has seemed like a roller coaster ride, with PPPs rising in the 2005 round relative to inflation rates, but falling in the 2011 round. The rest of this paper will explore these changes further.

\section{PPPs and market exchange rates}

We have seen that the 2011 ICP round shows a weaker relationship with domestic price changes than the prior round. There are a number of sources of discrepancies between the rates of change in domestic CPIs and PPPs. The PPP is a multilateral index while the CPI only reflects data for the country concerned. The weights in a PPP are formed by taking an average of weights for the country in question and those in the other countries being compared, while CPI weights naturally relate only to that country. For example, Deaton and Aten (2014) show that if one is using a Törnqvist index for the PPPs for two countries then the change (log difference) in the PPP for a given country will depend on both the difference in the CPI inflation rates and the differences in the weights used by the two CPIs. The extrapolation of PPPs using CPI inflation rates will only be exact if relative prices do not change in the two countries and the consumption patterns are the same. When comparing rich and poor countries large differences in consumption patterns can be expected.

The CPI and PPP indices can also differ because the underlying prices are different even if the weights are not. There are inherent differences between unilateral indices such as the CPIs and multilateral indices such as the PPPs. As Deaton and Aten (2014, p.12) explain:

"Cross-country indexes must match goods that are (a) identical in both locations, (b) reasonably commonly consumed in both places, so that the comparison lists for the ICP are usually quite different from the comparison lists of the CPI.”

The origins and implications of these differences are not well understood in the literature. One way of thinking about the difference is to draw on the distinction made by Deaton and Heston (2010) between "representativeness” and “comparability” in constructing price indices; the former relates to how well the commodity bundle represents consumption patterns in each country, while the latter refers to the comparability of bundles across borders. Comparability naturally has higher weight for international price indices-ICP price surveys would prefer to find the same commodity in different places to compare its prices - than national ones, where representativeness is all one cares about in selecting bundles to be priced. Indeed, beyond the use 
of internationally-accepted methods of measuring the CPI, there is no reason for a governmental statistics office to care about international comparability of the goods in its price schedule for the CPI.

This raises the possibility of TGP — that the ICP bundles may be weighted more heavily on internationally-traded goods than most domestic CPIs. Traded goods are automatically comparable across borders, while non-traded goods can differ greatly between countries even within a defined category of goods. One implication of such a TGP is that structural changes in developing economies may create divergence between PPPs and CPIs as more goods become tradable over time in a developing country. The DPE may come into play over time even controlling for CPI inflation. A higher weight on traded goods in the international price indices may well explain the PLI drift in the 2011 ICP.

If TGP exists in the ICP then changes in the MER between ICP rounds provide extra information, on top of the domestic price inflation rate for explaining any changes in PPPs not accountable to the latter. The MER will play a role to the extent that traded goods tend to get a higher weight in the ICP's PPPs than in domestic CPIs. This is intuitive; the Appendix outlines the idea in more formal terms. Of course, the CPI should still matter as it should be picking up domestic price movements due to non-traded goods (or imperfect substitutes). Both PPPs and CPI’s positively weight both traded and non-traded goods, but with different weights.

A key factor for explaining changes in the PLI is then the difference between the CPI inflation rate and the MER inflation rate. This is implied by TGP (as shown in the Appendix). Over the period 2005-11, MERs changed little on average, though they had been increasing on average in the prior period between ICP round (1993-2005). CPI inflation rates were lower in the later period. However, comparing 2005-11 and 1993-2005 the difference between the CPI and MER inflation rates rose sharply. Over 1993-05, the difference grew at an average annual rate of 2.354\% (s.e.=0.313) while for the period 2005-11 the rate more than doubled to 5.766 (s.e.0.273). This implies upward pressure on the PLI even if the 2011 round did not change its implicit weighting on traded goods.

Another factor that comes into play here is the new method of linking regional ICP results introduced in 2011 (World Bank, 2014). A new global list was developed first and then used to help create regional lists. By contrast, the method used in 2005 was implemented after regional lists were formed. It would not seem an unreasonable conjecture that, having set the 
global list in advance, the new method of linking regions in 2011 may well have (implicitly) increased the ICP's weight on internationally traded goods by influencing the regional lists.

Augmenting Equation (1) for the MER changes we obtain:

$$
\Delta \ln P P P_{i t}=\delta_{t}\left(1-U S_{i}\right)+\alpha_{1 t} \Delta_{t} \ln \left(D E F_{i t} / D E F_{t}^{U S}\right)+\alpha_{2 t} \Delta_{t} \ln M E R_{i t}+\mu_{i t}
$$

The parameters $\alpha_{1 t}$ and $\alpha_{2 t}$ are interpreted as the global average weights on CPI inflation and MER inflation in determining the rate of PPP inflation. The expectation is that $\alpha_{1 t}>0$ but that (under TGP) PPP inflation puts higher weight on traded goods' prices than do domestic CPIs so that $\alpha_{2 t}>0$ and $\alpha_{1 t}<0$. The derivation of (2) in the Appendix implies that $\alpha_{1 t}+\alpha_{2 t}=1$. The new drift parameter $\delta_{t}$ in (2) will include the global inflation rate for traded goods and the error term $\left(\mu_{i t}\right)$ will include heterogeneity across countries in the weights for a given round. Notice that one can also write (2) in terms of changes in the PLI: ${ }^{14}$

$$
\begin{aligned}
\Delta_{t} \ln P L I_{i t} & =\delta_{t}\left(1-U S_{i}\right)+\alpha_{1 t} \Delta_{t} \ln \left(D E F_{i t} / D E F_{t}^{U S}\right)+\left(\alpha_{2 t}-1\right) \Delta_{t} \ln M E R_{i t}+\mu_{i t} \\
& =\alpha_{0 t}+\alpha_{1 t} \Delta_{t} \ln \left(\frac{D E F_{i t}}{D E F_{t}^{U S} M E R_{i t}}\right)+\mu_{i t} \text { if } \alpha_{1 t}+\alpha_{2 t}=1
\end{aligned}
$$

This suggests an interpretation of (3) as the relationship between the two ways that the "real exchange rate" has been defined in applied work. The first is the MER normalized by the PPP (giving the inverse of the PLI) while the second is obtained when the MER is normalized instead by the domestic price deflator such as the CPI. (This is a measure of the "real exchange rate" one often finds in applied work.) We can postulate that there is some increasing relationship between these two measures of the real exchange rate. The parameter $\alpha_{1 t}$ can be interpreted as the elasticity of $M E R_{i t} / P P P_{i t}$ with respect to $M E R_{i t} / D E F_{i t}$.

Two special cases of Equation (2) are notable. First, if $\alpha_{1 t}=1, \alpha_{2 t}=0$ and $\varepsilon_{i t}=0$ then we get the extrapolation method between ICP rounds used by the WDI. Equation (2) is a generalization of this method. Second, if $\alpha_{1 t}=0, \alpha_{2 t}=1$ and $\varepsilon_{i t}=0$ then the model is consistent

\footnotetext{
${ }^{14}$ One can test the null that $\alpha_{1}+\alpha_{2}=1$ in (5) by regressing $\Delta \ln P L I_{i t}$ on $\Delta \ln \left(D E F_{i t} / M E R_{i t}\right)$ and $\Delta \ln M E R_{i t}$. The tests reported below are the t-tests on the coefficient on the latter variable.
} 
with the law-of-one-price for all goods in the PPP bundles. As we will see, neither special case is consistent with the data.

It is now clear that under TGP, the regression of the "PPP inflation rate" on the "CPI inflation rate" is miss-specified. Since we can also expect that $\Delta \ln C P I_{i t}$ and $\Delta \ln M E R_{i t}$ will be positively correlated, failing to control for exchange rate inflation will overestimate how much the PPPs have reflected the CPI inflation rates.

Turning to the data, Column (1) of Table 2 gives the regression of the change in the log PPP over 2005-11 on both the change in the log of the MER as well as CPI inflation rate (log difference in CPI). This is the regression specification in Equation (2). ${ }^{15}$ The result of Column (1) is distorted by four outliers with unusually large declines in the MER more than $40 \%$ per year (i.e., $\Delta_{t} \ln M E R_{i t}<-0.4$ ); see Figure 5. Dropping these, we get the results in Column (2). The restriction that the coefficients sum to unity is not rejected. The implied elasticity is 0.33 with a standard error of 0.07 . This is both significantly positive and significantly less than unity at the 1\% level. Column (3) gives the result when we confine the sample to the developing world (i.e., excluding the ICP's region 4, comprising Europe and the OECD). Now we find a higher weight on CPI inflation at 0.38 .

As noted, measurement errors in the CPI inflation rates may well be attenuating its coefficient in the regression for PPP inflation (although recall the comments on this point in Section 2). The elasticity rises notably when one uses the GDP deflator instead of the CPI. For the sample of developing countries, the results suggest that the weight on non-traded goods in the ICP is about half that in the CPIs.

Columns (1) and (2) of Table 3 give the corresponding regression using the 2005 revisions relative to 1993. (We return to Columns (3) and (4) in the next section). The model is fairly stable between ICP rounds except for the drift effects. Unlike the latest round, a positive PLI drift is indicated for the world as a whole outside the U.S. over 1993-2005. Again the sum of the coefficients on $\Delta \ln D E F$ and $\triangle \ln M E R$ is very close to unity. The results for the earlier round give an elasticity to CPI inflation of 0.36 and this is again both significantly positive and significantly less than unity at the $1 \%$ level. This is slightly higher than for the later period.

\footnotetext{
${ }^{15}$ Notice that, since the change in market exchange rates is a regressor, these can be equivalently thought of as regressions for the log PLI; just add unity to the coefficient on $\Delta \ln M E R_{i t}$ to switch to a regression using $\Delta \ln P P P_{i t}$ as the dependent variable; naturally the $\mathrm{R}^{2}$ changes.
} 
However, if we exclude Europe/OECD we see the expected increase in the coefficient, from 0.35 to 0.38 in the more recent period.

The empirical results for both the 2011 and 2005 revisions are consistent with TGP, i.e., the ICP appears to put a higher weight on internationally traded goods than do national CPIs. The downward PLI drift for the developing world emerges strongly when one uses the GDP deflator. There is no sign of PLI drift for Europe/OECD when one allows for TGP in the ICP.

When (2) is estimated with separate drift parameters one obtains $\hat{\delta}=0.220 \%$ (s.e. $=0.383 \%$ ) per annum for Europe/OECD (excluding U.S.) and -1.064 (0.496) for other countries.

Controlling for TGP, the 2011 ICP revisions have a larger unexplained variance than was the case for 2005. While only 5\% of the variance in PPP inflation rates of 1993-2005 is left unexplained, the proportion rises to $30 \%$ or more over $2005-11$.

\section{Introducing the Dynamic Penn Effect}

As discussed in the Introduction, one reason for rising PLIs is economic growth. Recall that the DPE postulates that the Penn Effect also holds over time, whereby faster growing developing countries tend to see rising price levels. Figure 3 plots the relationship found in the data between $\Delta \ln P L I_{i t}$ and growth rates for both periods; for 1993-2005 the estimate of slope is 0.283 (s.e. $=0.054 ; \mathrm{R}^{2}=0.212$ ); for the latest period the coefficient is $0.237(0.039)$. But it is not the slope of the DPE where a dramatic change is found. Rather, it is in the vertical level of the relationship - the intercepts. Panel (b) in Figure 3 gives both the actual DPE for 2005-11 and the predicted DPE using the relationship found for 1993-2005. As can be seen in Figure 3(b) there has been a roughly parallel downward shift in the DPE with the 2011 round.

To explore this change further, let us re-define the drift as the parameter $\delta_{t}$ in the following regression:

$$
\Delta_{t} \ln P L I_{i t}=\delta_{t}\left(1-U S_{i}\right)+\beta_{t} \Delta_{t} \ln \left(Y_{i t} / Y_{t}^{U S}\right)+\varepsilon_{i t}
$$

Here $P L I_{i t}$ and $Y_{i t}$ are the PLI and GDP per capita in \$US (respectively) for country $i$ in ICP round for date $t$. In Equation (4), both the PPP and GDP are normalized by the MER. 
Alternatively (4) can be written in the equivalent form as a regression of $\Delta_{t} \ln P L I_{i t}$ on the growth rate of GDP per capita at PPP, namely:

$$
\Delta_{t} \ln P L I_{i t}=\left(\frac{\delta_{t}}{1-\beta_{t}}\right)\left(1-U S_{i}\right)+\left(\frac{\beta_{t}}{1-\beta_{t}}\right) \Delta_{t} \ln \left(Y_{i t}^{P P P} / Y_{t}^{U S}\right)+\frac{\varepsilon_{i t}}{1-\beta_{t}}
$$

where $Y_{i t}^{P P P}$ is GDP per capita at PPP. The coefficients in (5) are exactly identified from those of (4). However, estimation using the form in (5) will not in general give the same results as (4) given that measurement errors entail that the appearance of the PPP on both sides of the regression in (5) (in the numerator of $P L I_{i t}$ and denominator of $Y_{i t}^{P P P}$ ) is likely to impart a downward bias to the regression coefficient in (5). This paper only uses the specification in (4).

The DPE and TGP can be thought of as competing models. However, there are two reasons for considering an encompassing model. First, one might expect the growth rate to have an effect conditional on the inflation rates in the CPI and MER. The GDP growth rates could be correlated with the error term in Equation (2) given that this contains country-specific weights. If traded goods tend to appear more often in the lists for more rapidly growing economies, such that the implicit weight on the MER rises, then this will be picked up by GDP growth rates.

Second, there has been a debate about whether it is GDP growth rates or domestic inflation rates that best explain PPP changes. Ravallion (2013a) found that the domestic inflation rate had little independent explanatory power once one allowed for the DPE. Inklaar (2013) questioned this finding and argued essentially the opposite: that the growth rate did not have extra power over the inflation rate. However, Inklaar did not estimate the encompassing modelthe nested test that would tell us which variable was more relevant (Ravallion, 2013b). I will use the encompassing model here. Readers do not need to take a position on the Inklaar-Ravallion debate-I allow both views.

Motivated by these observations, the encompassing model is: ${ }^{16}$

$$
\begin{aligned}
\Delta_{t} \ln P L I_{i t}=\delta_{t}\left(1-U S_{i}\right) & +\alpha_{1 t} \Delta_{t} \ln \left(D E F_{i t} / D E F_{t}^{U S}\right)+\left(\alpha_{2 t}-1\right) \Delta_{t} \ln M E R_{i t} \\
& +\beta_{t} \Delta_{t} \ln \left(Y_{i t} / Y_{t}^{U S}\right)+v_{i t}
\end{aligned}
$$

\footnotetext{
${ }^{16}$ Use of the log PLI as the dependent variable for the encompassing model is consistent with Penn Effect regressions are normally estimated in the literature. However, the regression is the same if one switches to log PPP; one just adds $\Delta \ln M E R_{i t}$ to both sides to get back to the form in Tables 2 and 3. I will include the corresponding values of the adjusted $\mathrm{R}^{2}$ to enable comparisons with the regressions in Table 2 .
} 
Notice that under the homogeneity restriction $\left(\alpha_{1 t}+\alpha_{2 t}=1\right)$ the three variables, the PPP, the CPI and GDP have the same deflator, namely the MER. Another way of saying this is that the nominal PPP is homogeneous of degree zero in the CPI and nominal GDP.

Table 4, Column (1), reports estimates of this augmented specification for the changes in the log PLI between 2005 and 2011 augmented to include GDP growth as in (6). Column (2) gives the result on dropping the four outliers mentioned above, while Column (4) gives the results dropping the "rich countries” (the ICP's Region 4, comprising Europe and OECD).

The GDP growth rate and the changes in ordinary exchange rates clearly play important roles. When weighted by its regression coefficient the variance in GDP growth rates represents 92\% to the variance in the changes in log PLIs. However, the growth rates are correlated with the inflation rates so the net increment to $\mathrm{R}^{2}$ from incorporating the DPE is not large. Adjusted $\mathrm{R}^{2}$ for changes in log PPP rates rises from 0.675 (Table 2, Column 2) to 0.711 (Table 4, Column 2).

Incorporating the DPE brings down the estimated effect of CPI inflation relative to MER inflation. The coefficient on CPI inflation is small and not significantly different from zero when one controls for GDP growth as well as MER changes. ${ }^{17}$ The aforementioned problems of attenuation bias in the impact of CPI inflation are still in play. If one uses instead the inflation rates based on GDP deflators then its coefficient in the regression matching Column (2) doubles to 0.194 (s.e.=0.104). However, this effect is still not strong in size or statistical significance (only significantly different from zero at the 6\% level). A stronger effect of emerges for the developing country sample (Column 5).

While there is little sign of PLI drift in 2011 using CPI inflation in the model allowing for the DPE, it again re-emerges on switching to the GDP deflators. For the developing world the downward PLI drift in the 2011 ICP is even stronger when one switches to GDP deflators, at 1.5\% per annum (Table 4, Column 5).

Some differences with the earlier ICP rounds are notable. Columns (3) and (4) of Table 3 give the corresponding result for 2005 relative to 1993. The coefficient on CPI inflation is now positive as expected. For the earlier period the sum of the coefficients on $\triangle \ln C P I$ and $\triangle \ln M E R$ in the regression for $\Delta \ln P P P$ is close to unity. Imposing this restriction one obtains $\hat{\alpha}_{1}=0.209$ (s.e. $=0.072$ ) - lower than when the DPE is ignored, but still both significantly positive and less

\footnotetext{
${ }^{17}$ In Column (6) if one imposes $\alpha_{1}+\alpha_{2}=1$ (the restriction passes statistically; $\mathrm{t}=0.50$ ) then the coefficient is 0.183 (s.e. $=0.117$ ) but this is not significantly different from zero at the $10 \%$ level.
} 
than unity. This also holds when one excludes the rich countries (Column (4), Table 3). By contrast to the 2005 round, the revisions in 2011 imply near zero elasticity of the real exchange rate deflated by the PPP to that obtained using the CPI deflator once one allows for the DPE.

Adding the extra controls, it is again confirmed that there is a positive PLI drift in the data for the earlier period. Also, while the DPE helps in explaining the changes, the share of unexplained variance is still substantially larger for the 2011 revisions than for 2005.

On controlling for these extra covariates of price levels there is no sign of a correlation between the implied revisions to the PLI and initial GDP per capita. This can be assessed by studying the residuals from the regressions in Table 4. A positive (negative) residual implies an upward (downward) revision in the 2011 PLI relative to what one would have expected based on the regressors and the 2005 PLI. Figure 6(a) plots the residuals from the regression in Column (2) of Table 4 against (log) GDP per capita in 2005. (The Figure looks similar using GDP per capita at PPP.) We see no sign of the pattern of downward revisions in poorer countries. Indeed, upward revisions appear more likely in low-income countries; if one drops the high-income countries (Europe/OECD) then the correlation coefficient rises to -0.30 (Figure 6(b)), which is significant at the $1 \%$ level. Average upward revisions are implied for the poorest countries, with downward revisions on average only emerging at levels of GDP per capita above about \$3,000 per year. The last row of Table 4 gives the coefficient on log GDP per capita for 2005 as an extra regressor; consistently with Figure 6(b) we see a significant negative correlation emerging for the developing countries. In other words, the implied PLI revisions controlling for both the TGP and DPE tended to be upwards for the poorest countries outside Europe and the OECD.

\section{Region-specific PLI drifts in the encompassing model}

The global drift in PPPs could reflect global factors, such as changes in traded goods prices (see the Appendix). However, as we will see, there are large differences across regions.

Table 5 augments the regressions in Table 4 by introducing dummy variables for the ICP regions for both periods to allow for region-specific drifts. ${ }^{18}$ The homogeneity restriction is

\footnotetext{
${ }^{18}$ Again the regressions are constrained to return a predicted value of zero for the change in the PLI for the U.S. Thus, for the regional breakdown in Table 5, a complete set of regional dummy variables is included. With no constant term, and the dummy variable for the U.S. is subtracted from that for ICP region 4 (Europe/OECD).
} 
imposed ( $\left.\alpha_{1}+\alpha_{2}=1\right)$. Results are given for both the DPE alone (Equation (4)) and the encompassing model, combining both the DPE and TGP (Equation (6)).

Whether one allows for TGP or DPE, there is no sign of PLI drift for Europe/OECD. However, adding the control for TGP increases the extent of PLI drift for Asia and Western Asia, but reduces the positive drifts for Latin America and Iran/Georgia.

There could still be region-specific economic effects not be picked up adequately by the covariates. One test for this is to exploit the fact that there is enough non-overlap in the regional groupings to add most World Bank regions. ${ }^{19}$ These will help pick up omitted regional economic factors. Column (6) of Table 5 gives the regression including dummy variables for the Bank's regions. These make very little difference to the results above. In particular, the two "Asia effects” are associated with the ICP regional groupings not the Bank's. The fact that the Asia regional drifts in the 2011 ICP are for the ICP regions, not World Bank regions, suggests that they may be related to unidentified differences in ICP implementation between the regional ICP authorities. $^{20}$

The regional pattern in the drift coefficients is negatively correlated with average GDP, although not significantly so. ${ }^{21}$ On controlling for ICP regions there is (again) no significant correlation between the residuals and GDP per capita ( $r=-0.08$, though rising to -0.16 when Europe/OECD is excluded). We see no sign that downward revisions are more likely in poorer countries within ICP regions.

China is of special interest since the 2005 ICP had been urban biased, as shown by Chen and Ravallion (2010b), while the 2011 round was more representative of the country as a whole. (Including rural prices will tend to reduce the PLI.) Could this explain the "Asia PLI drift”? On adding a dummy variable for China to the regression in Column (1) of Table 5 the coefficient is 0.025 (s.e.=0.005); China's PLI revision is positive. Of course, this is with a region effect for Asia, which also includes China. If one drops China from the Asia dummy variable then the

\footnotetext{
${ }^{19}$ The exception is the Bank's Sub-Saharan Africa, which overlaps too much with the ICP's “Africa” region credibly separate their effects; 44 of the 49 countries in the ICP's Africa region are in the World Bank's SubSaharan Africa.

${ }^{20}$ The Asia ICP office and the global office were invited to comment on this paper. The head of the Asia ICP office declined to do so. The global office kindly sent comments but they did not explain the Asia drift beyond referring to the Deaton-Aten paper discussed below.

${ }^{21}$ The correlation coefficients between the seven region drift coefficients in Column (5) of Table and mean log GDP per capita in 2005 \$US is -0.187; using GDP at PPP it is -0.143. Neither are significant at even the $10 \%$ level (prob. $=0.69$ and 0.76 respectively).
} 
China effect is negative, but not significantly different from zero (a coefficient of -0.008 , with s.e.=0.008). So the negative Asia effect is really "Asia except China."

\section{Implications for the Deaton-Aten hypothesis}

In the only prior effort to explain the seemingly puzzling findings of the 2011 ICP, Deaton and Aten (DA) (2014) argue that the 2011 ICP fixed a methodological problem with the 2005 round. ${ }^{22}$ Essentially, in their view the 2011 revisions undid mistakes in the 2005 ICP relate to how that round linked up the results obtained from its separate regional administrative units to form global PPPs. In the 2005 round the inter-regional linkage used a set of 18 "ring countries" spanning all regional units. These 18 countries did their own pricing exercise for a common list of goods. At the regional linkage stage, relative PPPs are kept fixed within the ICP regional groupings. ${ }^{23}$ In 2011, the ring method was replaced by a common global list, though still maintaining within-region fixity.

Following Deaton (2010), DA argue that the ring method used by the 2005 ICP resulted in an over-pricing in poor countries, which was corrected by the 2011 ICP round. The overpricing is seen to stem from the fact that the global list included many luxury goods that are hard to find in poor countries. It is claimed that these goods will only be found in a few exclusive places in poor countries and will be over-priced there. This is a conjecture. It is not clear why internationally-traded luxury goods will be over-priced in poorer countries. This would happen if there is imperfect completion in the market for luxury goods in poor countries, such that rich people in poor countries are exploited, but this is not spelt out explicitly in DA and I know of no supportive evidence. DA do not discuss any other methodological changes in the ICP.

Under the DA explanation, the regional structure of the ICP is the key to understanding the 2011 revisions. The changes should be primarily between regions. DA argue that we should expect to see strong regional effects in the revisions, with higher recorded prices in Africa and Asia. They argue that the pattern of PPP revisions at regional and country levels (in the latter

\footnotetext{
${ }^{22}$ Deaton and Aten were not writing in an official ICP capacity, although both were consultants to the 2011 ICP; Deaton was a member on its Technical Advisory Group and Aten was on its Computation Task Force. In their comments on the present paper, the ICP reported that "The ICP Results Review Group has also reviewed the Deaton-Aten paper on the ICP 2011 results and agrees with their findings.” The ICP Results Group comprises Angus Deaton, Erwin Diewert, Alan Heston, Paul McCarthy, Prasada Rao, and Fred Vogel who are also members of the ICP's Technical Advisory Group.

${ }^{23}$ This is a continuing feature of the ICP's methods that Deaton and Heston (2010) argue is primarily political in motivation not statistical, although see the comments in Ravallion (2010).
} 
case for the 18 "ring countries") is consistent with their explanation. ${ }^{24}$ They find that once the 2005 PPPs are adjusted for domestic inflation rates over 2005-11 the implied revisions in 2011 bring down the price levels in poorer countries relative to richer ones amongst the set of 18 ring countries. In a further check DA confirm that the revisions implied by their first method are consistent with the regional effects in the cross-country relationship between the PLI and consumption per capita. While DA's tests are consistent with their hypothesis related to the use of the ring method in 2005, but they do not establish that the 2011 revisions are solely due to an over-estimation of price levels in poor countries in 2005. The 2011 ICP may well be understating prices.

DA follow past practice in comparing new PPPs to extrapolations based solely on the rate of CPI inflation since the prior ICP round. We have seen that this special case is rejected empirically. In the light of the findings of the present paper, let us reexamine the DA explanation using a fuller set of data-consistent covariates.

Even prior to allowing for extra covariates, one aspect of the PPP changes in 2011 that is immediately troubling for the DA hypothesis is that (as noted in Section 2) the PPP drift relative to domestic price inflation is even greater for Europe/OECD than the developing world. Furthermore, the implied PPP revisions between 2005 and 2011 for the developing world that are not accountable to the extra covariates do not accord very well with the DA explanation. I confirm strong effects associated with country assignment to the ICP's regional administrative groupings as suggested by DA. However, using my extended model there is little sign of the regional pattern implied by the DA explanation for the changes in the 2011 ICP. The revisions do not comply with the pattern they suggest (with no sign of downward revisions in poorer regions/countries) and the bulk of the variance in the unexplained revisions is within regions not between them. ${ }^{25}$ Indeed, restricting attention to the developing world, the pattern of revisions in Figure 6(b) is exactly the opposite to that predicted by the DA hypothesis; poorer countries tended to see larger upward revisions to the PLIs in 2011.

\footnotetext{
${ }^{24}$ To test their explanation, DA compare the PPPs for 2005 for the 18 ring countries to their recalculated 2011 PPPs constructed for the same ring countries using the prices from the global list for 2011. Arguably this is not the most obvious test, which would be to re-run the 2011 ICP exercise globally using as close an approximation as possible to the 2005 ring method. DA do not explain their choice, though it undoubtedly reflects the data available to them.

${ }^{25}$ The regression in Column (1) of Table 5 leaves $44 \%$ of the variance in the changes in PLI unexplained. Of the share of the variance that is not explained, namely 77\% (Table 5, Column 3), the majority (about 60\%) is within ICP regions.
} 
Nor did the unexplained revisions to the 2011 ICP simply undo changes introduced in 2005. If one compares the residuals from Column (3) of Table 3 with those from Column (2) of Table 4 then one does find a negative correlation coefficient, but it is small at -0.171 and the regression coefficient of the residuals for 2011 (relative to 2005) on those for 2005 (relative to 1993 ) is -0.185 , with a standard error of 0.114 ; this is only significantly different from zero at the 11\% level. So less than 20\% of the upward revision to PLIs in 2005 was un-done in 2011. Confining the calculations to the developing world (i.e., excluding Europe/OECD) the relationship between the residuals is even weaker with a correlation coefficient of -0.146 and regression coefficient of -0.152 (s.e. $=0.121$ ) which is not significantly different from zero.

\section{Conclusions}

The ICP has been a very important source of data on price levels across countries. All defensible international comparisons of monetary aggregates require such data. However, the ICP has seemed something like a roller-coaster ride for developing countries, and the (large) community of users. Methods and data change in significant ways from one round to the next, and appear to differ between and within regions.

This paper has documented and studied the changes in PPPs in the 2005 and 2011 rounds of the ICP. The PPP had risen relative to domestic inflation rates in the 2005 ICP but fell again in the 2011 round. The new ICP indicates a downward drift of about 1\% per annum in price levels relative to market exchange rates at given growth rates for the developing world, reversing the upward trend seen in the 2005 ICP, relative to the 1993 round. The drift persists on also controlling for changes in market exchange rates as well as growth rates in GDP per capita. The downward drift is particularly strong for Asia and is associated with the ICP's country groupings for implementing the price surveys rather than the World Bank's regional groupings. This suggests that differences in ICP implementation have played a role, though the precise nature of those differences remains unclear.

While the 2011 ICP remains something of a mystery, in the process of trying to explain the downward drift in price levels, this study has taught us something about the ICP more generally. The hypothesis that the ICP's price surveys tend to use internationally traded goods more than do the domestic CPIs is a plausible conjecture on a priori grounds given that the ICP is an international survey of prices, which will understandably put a higher weight on 
comparability than national price surveys, for which representativeness is the overwhelming concern. While PPPs try to address the problem of the existence of non-traded goods, those goods can pose a problem for doing any international price surveys. International tradables are more likely to be comparable than non-tradables. This hypothesis is consistent with the evidence presented here on the predictive power of changes in the market exchange rate controlling for domestic inflation rates. To the extent that consumption patterns for tradables and non-tradables vary with consumption or income levels, this finding has implications for the use of the ICP in global poverty comparisons and inequality measures. Those implications merit further research. The evidence presented here also offers support for the practice in both growth empirics and poverty and inequality measurement of basing real income comparisons over time on domestic price indices rather than PPPs. At the same time, the results of this study point to limitations of PPPs for international comparisons. Adjustments for traded-goods preference may well be required in future work. 


\section{Appendix: Implications of TGP in the ICP}

The distinction between traded and non-traded goods does not have a clear mapping into standard commodity groupings. Food is both traded and non-traded. Even "services” now included internationally traded services. Suppose we re-group all goods into the traded/nontraded categories. Then, motivated by the argument above, consider the following equations for the changes in the PPP and the deflator for country $i$ and ICP round $t$ :

$$
\begin{aligned}
& \Delta_{t} \ln P P P_{i t}=S T_{i t}^{P P P} \Delta_{t} \ln P_{i t}^{T}+S N T_{i t}^{P P P} \Delta_{t} \ln P_{i t}^{N T}+e_{i t} \\
& \Delta_{t} \ln D E F_{i t}=S T_{i t}^{D E F} \Delta_{t} \ln P_{i t}^{T}+S N T_{i t}^{D E F} \Delta_{t} \ln P_{i t}^{N T}
\end{aligned}
$$

Here $S T_{i}^{P P P}$ and $S N T_{i}^{P P P}$ are the shares on internationally traded and non-traded goods (respectively) in the PPP rate for country $i$ while $S T_{i}^{D E F}$ and $S N T_{i}{ }^{D E F}$ are the corresponding shares in the CPI (with the shares summing to unity for each of PPP and CPI), while $\Delta_{t} \ln P_{i t}^{T}$ and $\Delta_{t} \ln P_{i t}^{N T}$ are the proportionate rates of change in the prices of traded and non-traded goods respectively. The "error term," $e_{i t}$, captures the extra terms stemming from the fact that the PPP is a multilateral index. (No such error term is required for the equation for the rate of domestic price inflation, although $\Delta_{t} \ln P_{i t}^{T}$ and $\Delta_{t} \ln P_{i t}^{N T}$ may well be measured with error.)

Now invoke the "law-of-one-price" for traded goods, implying that:

$$
\Delta_{t} \ln P_{i t}^{T}=\Delta_{t} \ln M E R_{i t}+\Delta_{t} \ln P_{t}^{T}
$$

where $\Delta \ln P_{t}^{T}$ denotes the rate of change in the world price of traded goods. Then we can readily derive the following equation for the rate of PPP inflation:

$$
\Delta_{t} \ln P P P_{i t}=\left(\frac{S N T_{i t}^{P P P}}{S N T_{i t}^{D E F}}\right) \Delta_{t} \ln D E F_{i t}+\left[S T_{i t}^{P P P}-\frac{S N T_{i t}^{P P P} S T_{i}^{D E F}}{S N T_{i t}^{D E F I}}\right] \Delta_{t} \ln M E R_{i t}+\varepsilon_{i t}
$$

where:

$$
\varepsilon_{i t}=e_{i t}-\frac{S N T_{i t}^{P P P} S T_{i t}^{D E F}}{S N T_{i t}^{D E F}} \Delta_{t} \ln P_{t}^{T}
$$


Notice that we cannot set $E\left(\varepsilon_{i t}\right)=0$ in general. For example, rising (falling) global prices of traded goods will generate positive (negative) drift in the PPPs. We see from (A3) that the rate of PPP inflation can be written as a weighted sum of the rates of domestic price inflation and the rate of change in the market exchange rate. The sum of the weights is unity, so we can re-write (A3) in an equivalent form, in terms of the rate of change in the PLI:

$$
\Delta_{t} \ln P L I_{i t}=\Delta_{t} \ln \left(P P P_{i t} / M E R_{i t}\right)=\left(\frac{S N T_{i t}^{P P P}}{S N T_{i t}^{D E F}}\right) \Delta_{t} \ln \left(D E F_{i t} / M E R_{i t}\right)+\varepsilon_{i t}
$$

If the domestic price deflator and PPP give the same weights on non-traded goods then the coefficient on the term in $\Delta \ln \left(D E F_{i t} / M E R_{i t}\right)$ in (A5) will be unity. Under TGP the coefficient is less than unity, though still positive. A higher weight on traded goods the 2011 ICP will thus yield a higher PLI at any given value of $\Delta \ln \left(D E F_{i t} / M E R_{i t}\right)$.

To obtain a regression specification we need to replace the coefficients in (A3) by their mean across the set of countries in the regression and transform the variables to assure that the PLI=1 for the U.S. This gives Equation (2) in the main text. 


\section{References}

Balassa, Bela, 1964, “The Purchasing Power Parity Doctrine: A Reappraisal,” Journal of Political Economy, 72: 584-596.

Bhagwati, Jagdish, 1984, “Why are Services Cheaper in Poor Countries?” Economic Journal, 94: 279-286.

Chandy, Lawrence, and Homi Kharas, 2014,“What Do New Price Data Mean For The Goal Of Ending Extreme Poverty?” Brookings, May 5.

Chen, Shaohua and Martin Ravallion, 2010a, “The Developing World is Poorer than we Thought, But no Less Successful in the Fight against Poverty,” Quarterly Journal of Economics, 125(4): 1577-1625. and , 2010b, "China is Poorer than we Thought, but no Less

Successful in the Fight Against Poverty," in Debates on the Measurement of Poverty, Sudhir Anand, Paul Segal, and Joseph Stiglitz, eds. (Oxford, UK: Oxford University Press). Crucini, Mario and Hakan Yilmazkuday, 2014, “Understanding Log-Run Price Dispersion,” Journal of Monetary Economics 66: 226-240.

Deaton, Angus, 2010, "Price Indices, Inequality and the Measurement of World Poverty," American Economic Review 100(1): 5-34.

Deaton, Angus and Bettina Aten, 2014, “Trying to Understand the PPPs in ICP 2011: Why are the Results so Different?” NBER Working Paper 20244, National Bureau of Economic Research, Cambridge, Mass.

Deaton, Angus, and Alan Heston, 2010, “Understanding PPPs and PPP-Based National Accounts,” American Economic Journal: Macroeconomics 2(4): 1-35.

Dykstra, Sarah, Charles Kenny, and Justin Sandefur, 2014, “Global Absolute Poverty fell by Almost Half on Tuesday,” Center for Global Development, May 2

Inklaar, Robert, 2013, "Price Levels and Economic Growth: Making Sense of Revisions to Data on Real Incomes-A Comment,” Review of Income and Wealth, 59(4): 614-22.

Johnson, Simon, William Larson, Chris Papageorgiou, and Arvind Subramanian, 2013, “Is Newer Better? The Penn World Table Revisions and their Impact of Growth Estimates,” Journal of Monetary Economics 60(2): 255-274. 
Lewis, Arthur, 1954, “Economic Development with Unlimited Supplies of Labor,” Manchester School of Economic and Social Studies 22: 139-191.

Nuxoll, Daniel A., 1994, “Differences in Relative Prices and International Differences in Growth Rates,” American Economic Review 84(5), 1423-1436.

Ravallion, Martin, 2010, “Understanding PPPs and PPP-Based National Accounts: A Comment,” American Economic Journal: Macroeconomics, 2(4): 46-52.

_, 2013a, “Price Levels and Economic Growth,” Review of Income and Wealth 59(4): 593-613.

, 2013b, “Reply to Inklaar,” Review of Income and Wealth 59(4): 623-628.

Rogoff, Kenneth, 1996, “The Purchasing Power Parity Puzzle,” Journal of Economic Literature, 34(2): 647-668.

Samuelson, Paul, 1964, “Theoretical Notes on Trade Problems,” Review of Economics and Statistics, 46: 145-154.

Summers, Robert, and Alan Heston, 1991, “The Penn World Table (Mark 5): An Extended Set of International Comparisons, 1950-1988,” Quarterly Journal of Economics, 106: 327368.

World Bank, 2008a, Global Purchasing Power Parities and Real Expenditures. 2005

International Comparison Program, World Bank, Washington DC. , 2008b, Comparisons of New 2005 PPPs with Previous Estimates. (Revised Appendix G to World Bank 2008a), World Bank, Washington DC. , 2013, World Development Indicators, World Bank, Washington DC. , 2014, Purchasing Power Parities and Real Expenditures of World Economies, World Bank, Washington DC. 
Table 1: Price level changes between ICP rounds

\begin{tabular}{|c|c|c|c|}
\hline & $\begin{array}{l}\text { (1) } \\
\text { Number of countries } \\
\text { in } 2005 \text { round }\end{array}$ & $\begin{array}{c}(2) \\
\text { Rate of change } \\
\text { in PLI } \\
2005-2011 \\
\text { (\% per annum) }\end{array}$ & $\begin{array}{c}(3) \\
\text { Rate of change } \\
\text { in PLI } \\
1993-2005 \\
\text { (\% per annum) }\end{array}$ \\
\hline $\begin{array}{l}\text { All countries } \\
\text { (except U.S) }\end{array}$ & 147 & $\begin{array}{c}1.327 * * * \\
(0.223)\end{array}$ & $\begin{array}{c}1.347 * * * \\
(0.218)\end{array}$ \\
\hline $\begin{array}{l}\text { Europe/OECD } \\
\text { (except U.S.) }\end{array}$ & 43 & $\begin{array}{c}1.464 * * * \\
(0.305)\end{array}$ & $\begin{array}{c}1.823 * * * \\
(0.312)\end{array}$ \\
\hline Other countries & 104 & $\begin{array}{c}1.274 * * * \\
(0.299)\end{array}$ & $\begin{array}{c}1.132 * * * \\
(0.285)\end{array}$ \\
\hline \multicolumn{4}{|l|}{ ICP regions } \\
\hline 1: Africa & 48 & $\begin{array}{c}1.112 * * * \\
(0.317)\end{array}$ & $\begin{array}{c}1.666^{* * *} \\
(0.403)\end{array}$ \\
\hline 2: Asia & 22 & $\begin{array}{l}-0.038 \\
(0.473)\end{array}$ & $\begin{array}{l}1.514^{* *} \\
(0.750)\end{array}$ \\
\hline 3: CIS & 8 & $\begin{array}{l}4.265 * * * \\
(0.843)\end{array}$ & $\begin{array}{l}1.257^{*} \\
(0.659)\end{array}$ \\
\hline $\begin{array}{l}\text { 4: Europe/OECD } \\
\text { (excl.U.S) }\end{array}$ & 48 & $\begin{array}{c}1.433 * * * \\
(0.304)\end{array}$ & $\begin{array}{c}1.782^{* * *} \\
(0.312)\end{array}$ \\
\hline 5: Latin America & 9 & $\begin{array}{c}5.448 * * * \\
(0.746)\end{array}$ & $\begin{array}{l}-0.678 \\
(0.755)\end{array}$ \\
\hline 6: Western Asia & 10 & $\begin{array}{l}-2.255^{* * *} \\
(0.743)\end{array}$ & $\begin{array}{l}-0.788 \\
(0.646)\end{array}$ \\
\hline 7: Iran and Georgia & 2 & $\begin{array}{c}5.075 * * * \\
(0.972)\end{array}$ & $\begin{array}{l}1.214^{*} \\
(0.708)\end{array}$ \\
\hline
\end{tabular}

Note: Columns (2) and (3) give rates of change in the PLI, measured by (unconditional mean annualized changes in logs). White heteroskedasticity-consistent standard errors in parentheses. ${ }^{* * *}$ : significant at the $1 \%$ level; ** significant at the $5 \%$ level; * at $10 \%$. 
Table 2: Regression for annualized difference in $\log$ PPP between 2005 and 2011 ICP rounds

(1) (3) (3)

\begin{tabular}{|c|c|c|c|c|c|}
\hline Deflator & CPI & CPI & $\begin{array}{c}(3) \\
\text { Excl. Europe/ } \\
\text { OECD } \\
\text { CPI }\end{array}$ & GDP deflator & $\begin{array}{c}\text { (5) } \\
\text { Excl. Europe/ } \\
\text { OECD } \\
\text { GDP deflator }\end{array}$ \\
\hline PLI drift $\left(\hat{\delta}_{t}\right)$ & 0.009 & $\begin{array}{c}0.002 \\
0.003)\end{array}$ & -0.003 & -0.002 & $\begin{array}{c}-0.012 * * \\
(0.005)\end{array}$ \\
\hline $\begin{array}{l}\text { Annualize difference in log } \\
\text { deflator }\left(\hat{\alpha}_{1 t}\right)\end{array}$ & $\begin{array}{l}0.093^{*} \\
(0.050)\end{array}$ & $\begin{array}{c}0.307 * * * \\
(0.090)\end{array}$ & $\begin{array}{c}0.384 * * * \\
(0.116)\end{array}$ & $\begin{array}{c}0.345^{* * * *} \\
(0.076)\end{array}$ & $\begin{array}{c}0.459 * * * \\
(0.088)\end{array}$ \\
\hline $\begin{array}{l}\text { Annualized difference in log } \\
\text { market exchange rate }\left(\hat{\alpha}_{2 t}\right)\end{array}$ & $\begin{array}{c}0.965 * * * \\
(0.016)\end{array}$ & $\begin{array}{c}0.653 * * * \\
(0.103)\end{array}$ & $\begin{array}{c}0.620 * * * \\
(0.123)\end{array}$ & $\begin{array}{c}0.599 * * * \\
(0.096)\end{array}$ & $\begin{array}{c}0.524 * * * \\
(0.094)\end{array}$ \\
\hline $\mathrm{R}^{2}$ & 0.954 & 0.679 & 0.674 & 0.714 & 0.717 \\
\hline Adjusted $\mathrm{R}^{2}$ & 0.954 & 0.675 & 0.667 & 0.710 & 0.711 \\
\hline $\mathrm{N}$ & 141 & 137 & 93 & 134 & 91 \\
\hline S.E. of regression & 0.026 & 0.025 & 0.028 & 0.024 & 0.026 \\
\hline F-statistic & 1439.267 & 142.306 & 93.098 & 163.492 & 111.532 \\
\hline Prob. F & 0.000 & 0.000 & 0.000 & 0.000 & 0.000 \\
\hline $\begin{array}{l}\text { t-test for homogeneity } \\
\left(\hat{\alpha}_{1 t}+\hat{\alpha}_{2 t}=1\right)\end{array}$ & 1.199 & -0.707 & 0.050 & -1.091 & -0.296 \\
\hline$\hat{\alpha}_{1 t}$ imposing homogeneity & $\begin{array}{c}0.037 * * \\
(0.019)\end{array}$ & $\begin{array}{c}0.326 * * * \\
(0.067)\end{array}$ & $\begin{array}{c}0.382 * * * \\
(0.102)\end{array}$ & $\begin{array}{c}0.360 * * * \\
(0.076)\end{array}$ & $\begin{array}{c}0.464 * * * \\
(0.086)\end{array}$ \\
\hline
\end{tabular}

Note: The dependent variable is the annualized difference in the log price level index (ratio of the PPP exchange rate to the MER) between 2005 and 2011. Regressors are transformed such that the predicted value is zero for the U.S. (as in Equation (1) in text). The change in the log of the CPI for the U.S. over 2005-11 was 0.1413, while the change in the GDP deflator was 0.1150 . White heteroskedasticity-consistent standard errors. ${ }^{* * *}$ : significant at the $1 \%$ level; ** significant at the $5 \%$ level; * $10 \%$ level. Columns (2) and (4) drops four outliers from the regression in Column (1) with unusually large devaluations (see Figure 5 and text). The one remaining outlier amongst these four was also dropped from Column (3) and (5). 
Table 3: Regression for annualized difference in log PPP between 1993 and 2005 ICP rounds

\begin{tabular}{|c|c|c|c|c|}
\hline & (1) & $\begin{array}{c}(2) \\
\text { Excl. Europe/ } \\
\text { OECD }\end{array}$ & (3) & $\begin{array}{c}(4) \\
\text { Excl. Europe/ } \\
\text { OECD }\end{array}$ \\
\hline PLI drift $\left(\hat{\delta}_{t}\right)$ & $\begin{array}{c}0.014^{* * *} \\
(0.003)\end{array}$ & $\begin{array}{c}0.016 * * * \\
(0.005)\end{array}$ & $\begin{array}{c}0.010 * * * \\
(0.002)\end{array}$ & $\begin{array}{c}0.013 * * * \\
(0.005)\end{array}$ \\
\hline $\begin{array}{l}\text { Annualize difference in log } \\
\text { Consumer Price Index }\left(\hat{\alpha}_{1 t}\right)\end{array}$ & $\begin{array}{c}0.358 * * * \\
(0.062)\end{array}$ & $\begin{array}{c}0.374 * * * \\
(0.086)\end{array}$ & $\begin{array}{c}0.206^{* * *} \\
(0.074)\end{array}$ & $\begin{array}{c}0.279 * * * \\
(0.094)\end{array}$ \\
\hline $\begin{array}{l}\text { Annualized difference in log } \\
\text { market exchange rate }\left(\hat{\alpha}_{2 t}\right)\end{array}$ & $\begin{array}{c}0.640 * * * \\
(0.068)\end{array}$ & $\begin{array}{c}0.613^{* * *} \\
(0.098)\end{array}$ & $\begin{array}{c}0.799 * * * \\
(0.079)\end{array}$ & $\begin{array}{c}0.712 * * * \\
(0.107)\end{array}$ \\
\hline $\begin{array}{l}\text { Annualized difference in log } \\
\text { GDP per capita in \$US }(\hat{\beta})\end{array}$ & n.a. & n.a. & $\begin{array}{c}0.242 * * * \\
(0.065)\end{array}$ & $\begin{array}{c}0.168 * * * \\
(0.066)\end{array}$ \\
\hline $\mathrm{R}^{2}$ & 0.952 & 0.932 & 0.959 & 0.937 \\
\hline Adjusted $\mathrm{R}^{2}$ & 0.951 & 0.930 & 0.957 & 0.934 \\
\hline $\mathrm{N}$ & 116 & 73 & 115 & 72 \\
\hline S.E. of regression & 0.023 & 0.026 & 0.021 & 0.025 \\
\hline F-statistic & 1121.762 & 482.72 & 854.103 & 338.687 \\
\hline Prob. F & 0.000 & 0.000 & 0.000 & 0.000 \\
\hline $\begin{array}{l}\text { t-test for homogeneity } \\
\left(\hat{\alpha}_{1 t}+\hat{\alpha}_{2 t}=1\right)\end{array}$ & -0.132 & -0.456 & -0.362 & -0.308 \\
\hline$\hat{\alpha}_{1 t}$ imposing homogeneity & $\begin{array}{c}0.359 * * * \\
(0.068)\end{array}$ & $\begin{array}{c}0.352 * * * \\
(0.105)\end{array}$ & $\begin{array}{c}0.209 * * * \\
(0.072)\end{array}$ & $\begin{array}{c}0.270 * * * \\
(0.090)\end{array}$ \\
\hline
\end{tabular}

Note: The dependent variable is the annualized difference in the log price level index (ratio of the PPP exchange rate to the ordinary exchange rate) between 1993 and 2005. Regressors are transformed such that the predicted value is zero for the U.S. (as in Equation (1) in text). The change in the log of the CPI for the U.S. over 1993-2005 was 0.3015 , while the changes in the GDP deflator and GDP per capita were 0.1234 and 0.4948 respectively. White heteroskedasticity-consistent standard errors. ${ }^{* * *}$ : significant at the $1 \%$ level; ** significant at the $5 \%$ level; * $10 \%$ level. 
Table 4: Regression for annualized difference in log PLI between 2005 and 2011 ICP rounds incorporating the Dynamic Penn Effect

\begin{tabular}{|c|c|c|c|c|c|}
\hline Deflator & CPI & CPI & $\begin{array}{c}(3) \\
\text { Excl. Europe/ } \\
\text { OECD } \\
\text { CPI }\end{array}$ & $\begin{array}{c}\text { (4) } \\
\text { GDP deflator }\end{array}$ & $\begin{array}{c}\text { (5) } \\
\text { Excl. Europe } \\
\text { OECD } \\
\text { GDP deflator }\end{array}$ \\
\hline PLI drift $\left(\hat{\delta}_{t}\right)$ & $\begin{array}{l}-0.003 \\
(0.003)\end{array}$ & $\begin{array}{l}-0.004 \\
(0.003)\end{array}$ & $\begin{array}{l}-0.011^{*} \\
(0.006)\end{array}$ & $\begin{array}{l}-0.005^{*} \\
(0.003)\end{array}$ & $\begin{array}{l}-0.015^{* * *} \\
(0.006)\end{array}$ \\
\hline $\begin{array}{l}\text { Annualize difference in log } \\
\text { deflator }\left(\hat{\alpha}_{1 t}\right)\end{array}$ & $\begin{array}{l}-0.052 \\
(0.052)\end{array}$ & $\begin{array}{c}0.085 \\
(0.094)\end{array}$ & $\begin{array}{c}0.165 \\
(0.123)\end{array}$ & $\begin{array}{l}0.195^{*} \\
(0.104)\end{array}$ & $\begin{array}{c}0.313^{* * *} \\
(0.114)\end{array}$ \\
\hline $\begin{array}{l}\text { Annualized difference in } \\
\log \operatorname{MER}\left(\hat{\alpha}_{2 t}\right)\end{array}$ & $\begin{array}{c}-0.028 * * * \\
(0.008)\end{array}$ & $\begin{array}{c}-0.187 * * \\
(0.089)\end{array}$ & $\begin{array}{l}-0.195^{*} \\
(0.120)\end{array}$ & $\begin{array}{l}-0.282^{* * *} \\
(0.105)\end{array}$ & $\begin{array}{c}-0.341^{* * *} \\
(0.113)\end{array}$ \\
\hline $\begin{array}{l}\text { Annualized diff. in log GDP } \\
\text { per capita in \$US }(\hat{\beta})\end{array}$ & $\begin{array}{c}0.258 * * * \\
(0.044)\end{array}$ & $\begin{array}{c}0.209 * * * \\
(0.048)\end{array}$ & $\begin{array}{c}0.216 * * * \\
(0.060)\end{array}$ & $\begin{array}{c}0.144^{* *} \\
(0.056)\end{array}$ & $\begin{array}{c}0.137 * * \\
(0.063)\end{array}$ \\
\hline $\mathrm{R}^{2}$ & 0.236 & 0.254 & 0.237 & 0.277 & 0.280 \\
\hline Adjusted $\mathrm{R}^{2}$ & 0.219 & 0.237 & 0.211 & 0.260 & 0.255 \\
\hline $\begin{array}{l}\text { Adjusted } \mathrm{R}^{2} \text { for the } \log \mathrm{PPP} \\
\text { specification }\end{array}$ & 0.963 & 0.711 & 0.703 & 0.722 & 0.720 \\
\hline $\mathrm{N}$ & 140 & 136 & 92 & 133 & 90 \\
\hline S.E. of regression & 0.024 & 0.024 & 0.026 & 0.023 & 0.026 \\
\hline F-statistic & 14.027 & 14.947 & 9.121 & 16.441 & 11.128 \\
\hline Prob. F & 0.000 & 0.000 & 0.000 & 0.000 & 0.000 \\
\hline $\begin{array}{l}\text { Coefficient on } 2005 \text { GDP } \\
\text { per capita as extra regressor }\end{array}$ & $\begin{array}{l}-0.000 \\
(0.001)\end{array}$ & $\begin{array}{l}-0.001 \\
(0.001)\end{array}$ & $\begin{array}{l}-0.005^{* * *} \\
(0.002)\end{array}$ & $\begin{array}{l}-0.000 \\
(0.001)\end{array}$ & $\begin{array}{l}-0.006^{* * *} \\
(0.002)\end{array}$ \\
\hline
\end{tabular}

Note: The dependent variable is the annualized difference in the log price level index (ratio of the PPP exchange rate to the ordinary exchange rate) between 2005 and 2011. Regressors are transformed such that the predicted value is zero for the U.S. (as in Equation (1) in text). The change in the log of the CPI for the U.S. over 2005-11 was 0.1413, while the changes in the GDP deflator and GDP per capita were 0.1150 and 0.1778 respectively. White heteroskedasticity-consistent standard errors. ***: significant at the 1\% level; ** significant at the 5\% level; * 10\% level. Columns (2) and (4) drop four outliers from the regression in Column (1); see Figure 5 and text. The one remaining outlier amongst these four was also dropped from Column (3) and (5). 
Table 5: Regression for annualized difference in log PLI imposing homogeneity and with region-specific drifts $2005-11$

\begin{tabular}{|c|c|c|c|c|c|c|}
\hline & $\begin{array}{c}(1) \\
\text { DPE only }\end{array}$ & $\begin{array}{c}(2) \\
\text { TGP only }\end{array}$ & $\begin{array}{c}(3) \\
\text { DPE+TGP }\end{array}$ & $\begin{array}{c}(4) \\
\text { DPE only }\end{array}$ & $\begin{array}{c}(5) \\
\text { DPE+TGP }\end{array}$ & $\begin{array}{c}(6) \\
\text { DPE+TGP }\end{array}$ \\
\hline $\begin{array}{l}\text { Annualized difference in log } \\
\text { GDP per capita in \$US }(\hat{\beta})\end{array}$ & $\begin{array}{c}0.285^{* * *} \\
(0.051)\end{array}$ & & $\begin{array}{c}0.160 * * * \\
(0.059)\end{array}$ & $\begin{array}{c}0.245^{* * *} \\
(0.045)\end{array}$ & $\begin{array}{c}0.126^{* * *} \\
(0.052)\end{array}$ & $\begin{array}{c}0.148 * * * \\
(0.056)\end{array}$ \\
\hline $\begin{array}{l}\text { Annualized difference between } \\
\text { inflation rates for GDP deflator } \\
\text { and } \operatorname{MER}\left(\hat{\alpha}_{1 t}=1-\hat{\alpha}_{2 t}\right)\end{array}$ & & $\begin{array}{c}0.430 * * * \\
(0.082)\end{array}$ & $\begin{array}{c}0.287 * * * \\
(0.094)\end{array}$ & & $\begin{array}{c}0.293^{* * *} \\
(0.093)\end{array}$ & $\begin{array}{c}0.302^{* * *} \\
(0.091)\end{array}$ \\
\hline \multicolumn{7}{|l|}{ PLI drift $\left(\hat{\delta}_{t}\right)(\mathbf{x 1 0 0})$} \\
\hline $\begin{array}{l}\text { Europe/OECD (excl. U.S.) } \\
\text { (x100) } \\
\text { Other countries }\end{array}$ & $\begin{array}{c}0.322 \\
(0.285) \\
-1.001^{* *} \\
(0.484)\end{array}$ & $\begin{array}{c}0.270 \\
(0.383) \\
-1.064 * * \\
(0.496)\end{array}$ & $\begin{array}{c}0.030 \\
(0.299) \\
-1.585^{* * *} \\
(0.458)\end{array}$ & & & \\
\hline \multicolumn{7}{|l|}{ ICP regions } \\
\hline 1: Africa & & & & $\begin{array}{c}-0.352 \\
(0.446)\end{array}$ & $\begin{array}{c}-0.876^{* *} \\
(0.407)\end{array}$ & $\begin{array}{c}-0.961^{* *} \\
(0.419)\end{array}$ \\
\hline 2: Asia & & & & $\begin{array}{c}-2.304^{* * *} \\
(0.575)\end{array}$ & $\begin{array}{c}-2.706^{* * *} \\
(0.587)\end{array}$ & $\begin{array}{c}-2.432 * * * \\
(0.951)\end{array}$ \\
\hline 3: CIS & & & & $\begin{array}{c}1.242 \\
(1.010)\end{array}$ & $\begin{array}{c}0.346 \\
(0.889)\end{array}$ & $\begin{array}{c}0.995 \\
(0.940)\end{array}$ \\
\hline 4: Europe/OECD (excl. U.S.) & & & & $\begin{array}{c}0.395 \\
(0.291)\end{array}$ & $\begin{array}{c}0.138 \\
(0.309)\end{array}$ & $\begin{array}{c}0.444 \\
(0.335)\end{array}$ \\
\hline 5: Latin America & & & & $\begin{array}{c}2.787 * * * \\
(0.836)\end{array}$ & $\begin{array}{l}1.698^{* *} \\
(0.803)\end{array}$ & $\begin{array}{c}2.514 * * \\
(1.007)\end{array}$ \\
\hline 6: Western Asia & & & & $\begin{array}{c}-4.087 * * * \\
(0.652)\end{array}$ & $\begin{array}{c}-5.332 * * * \\
(0.661)\end{array}$ & $\begin{array}{c}-5.086 * * * \\
(0.679)\end{array}$ \\
\hline 7: Iran and Georgia & & & & $\begin{array}{c}2.348^{* *} \\
(1.024)\end{array}$ & $\begin{array}{c}1.196 \\
(0.756)\end{array}$ & $\begin{array}{c}2.001 * * \\
(0.873)\end{array}$ \\
\hline \multicolumn{7}{|l|}{ World Bank regions } \\
\hline 1: East Asia & & & & & & $\begin{array}{c}-0.417 \\
(1.051)\end{array}$ \\
\hline 2: Eastern Europe and Central & & & & & & $-0.982 * *$ \\
\hline Asia & & & & & & $(0.501)$ \\
\hline 3: Latin America and & & & & & & $-1.144^{*}$ \\
\hline Caribbean & & & & & & $(0.672)$ \\
\hline 4: Middle East and North & & & & & & -1.250 \\
\hline Africa & & & & & & $(0.773)$ \\
\hline 5: South Asia & & & & & & $\begin{array}{l}-1.040 \\
(0.910)\end{array}$ \\
\hline $\mathrm{R}^{2}$ & 0.253 & 0.276 & 0.324 & 0.539 & 0.605 & 0.625 \\
\hline Adjusted $\mathrm{R}^{2}$ & 0.242 & 0.265 & 0.308 & 0.514 & 0.579 & 0.584 \\
\hline $\mathrm{N}$ & 136 & 134 & 133 & 136 & 133 & 133 \\
\hline S.E. of regression & 0.024 & 0.023 & 0.022 & 0.019 & 0.019 & 0.018 \\
\hline F-statistic & 14.926 & 16.486 & 15.318 & 21.058 & 20.914 & 14.022 \\
\hline Prob. F & 0.000 & 0.000 & 0.000 & 0.000 & 0.000 & 0.000 \\
\hline
\end{tabular}

Note: See Table 4. 
Figure 1: Densities of changes in log price level index (PLI) between ICP rounds

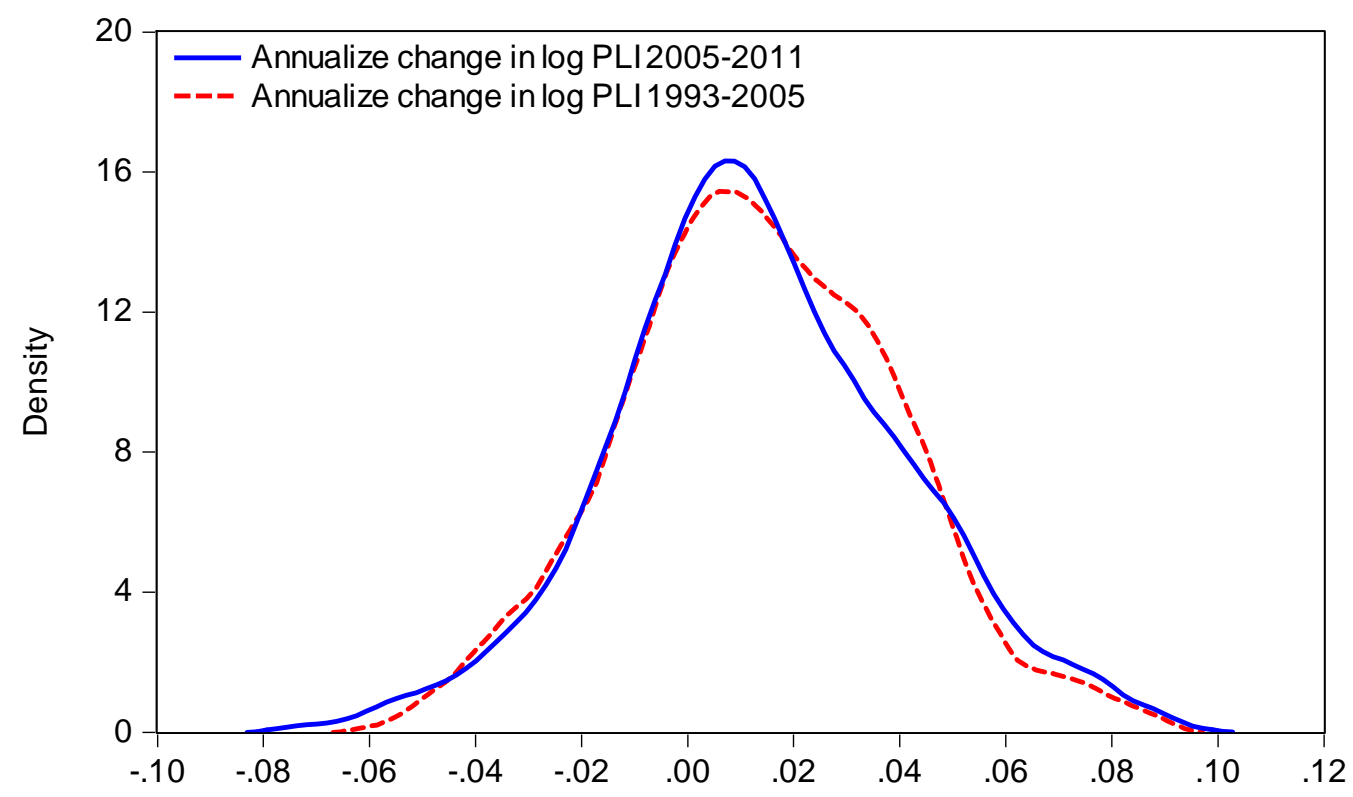

Figure 2: Changes in log PLI at country level between successive ICP rounds

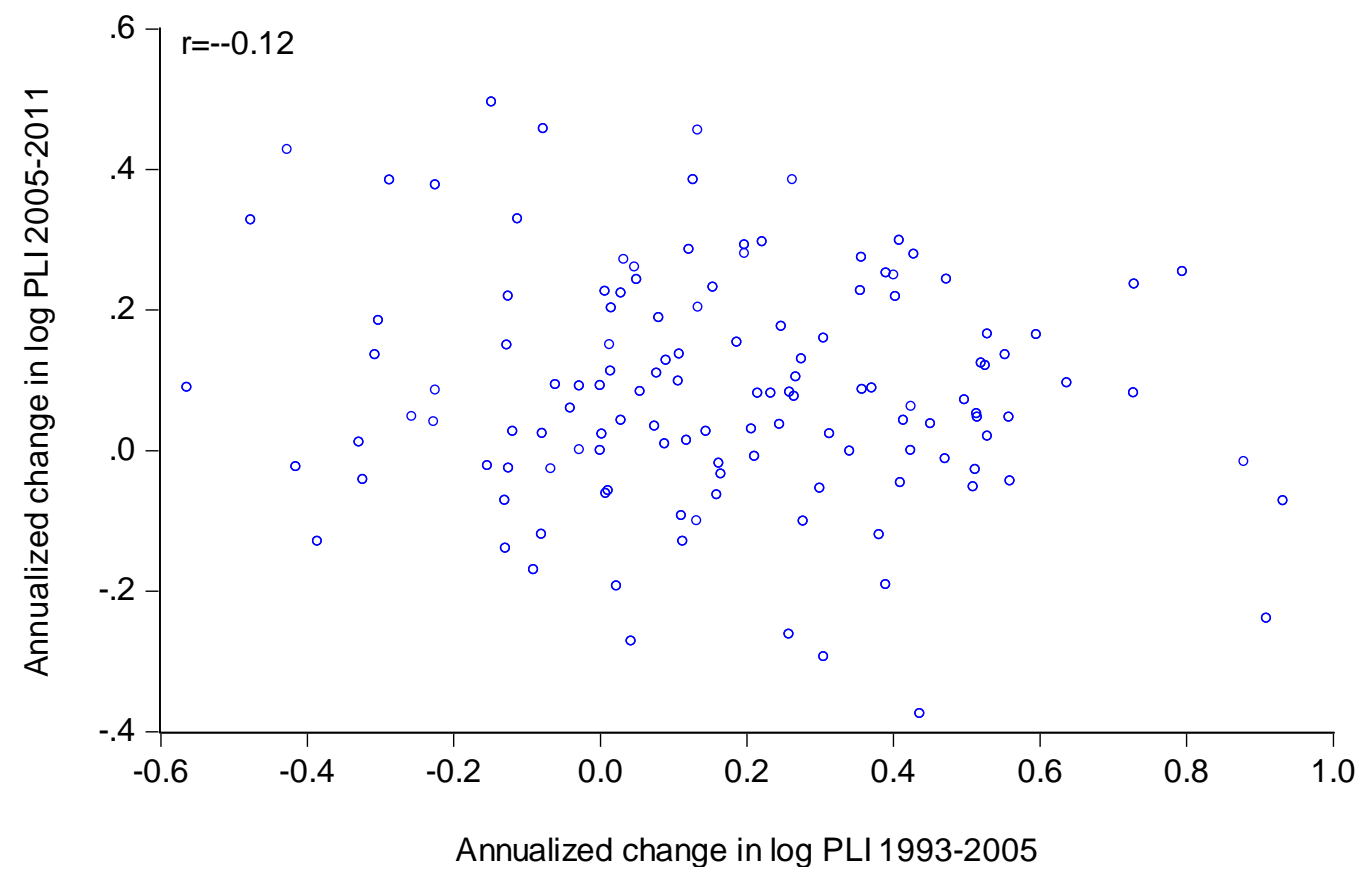




\section{Figure 3: Dynamic Penn Effect}

(a) $1993-2005$

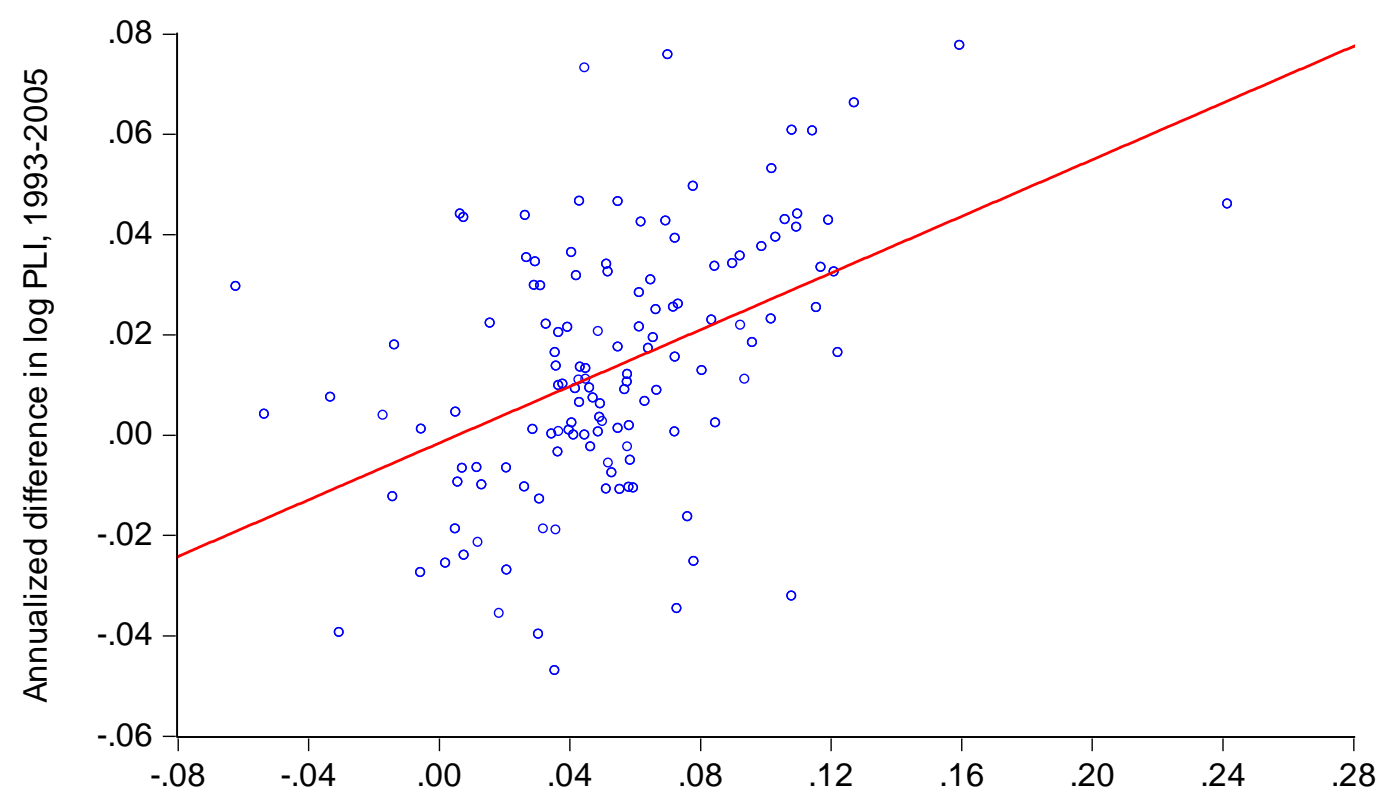

Annual growth rate of GDP per capita in \$US, 1993-2005

(b) $2005-2011$

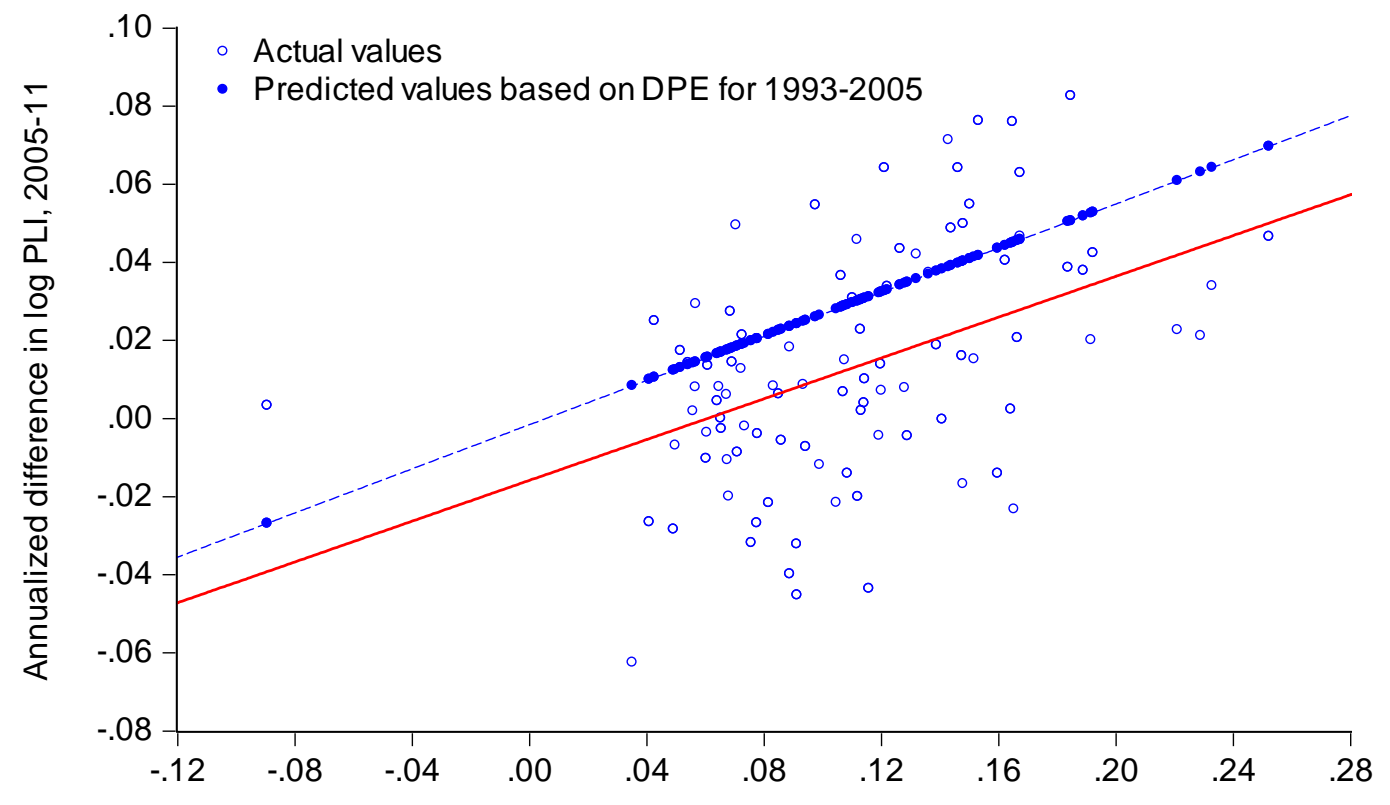

Annual growth rate of GDP per capita in \$US, 2005-11 
Figure 4: PPP inflation plotted against CPI inflation between ICP rounds

(a) 1993-2005

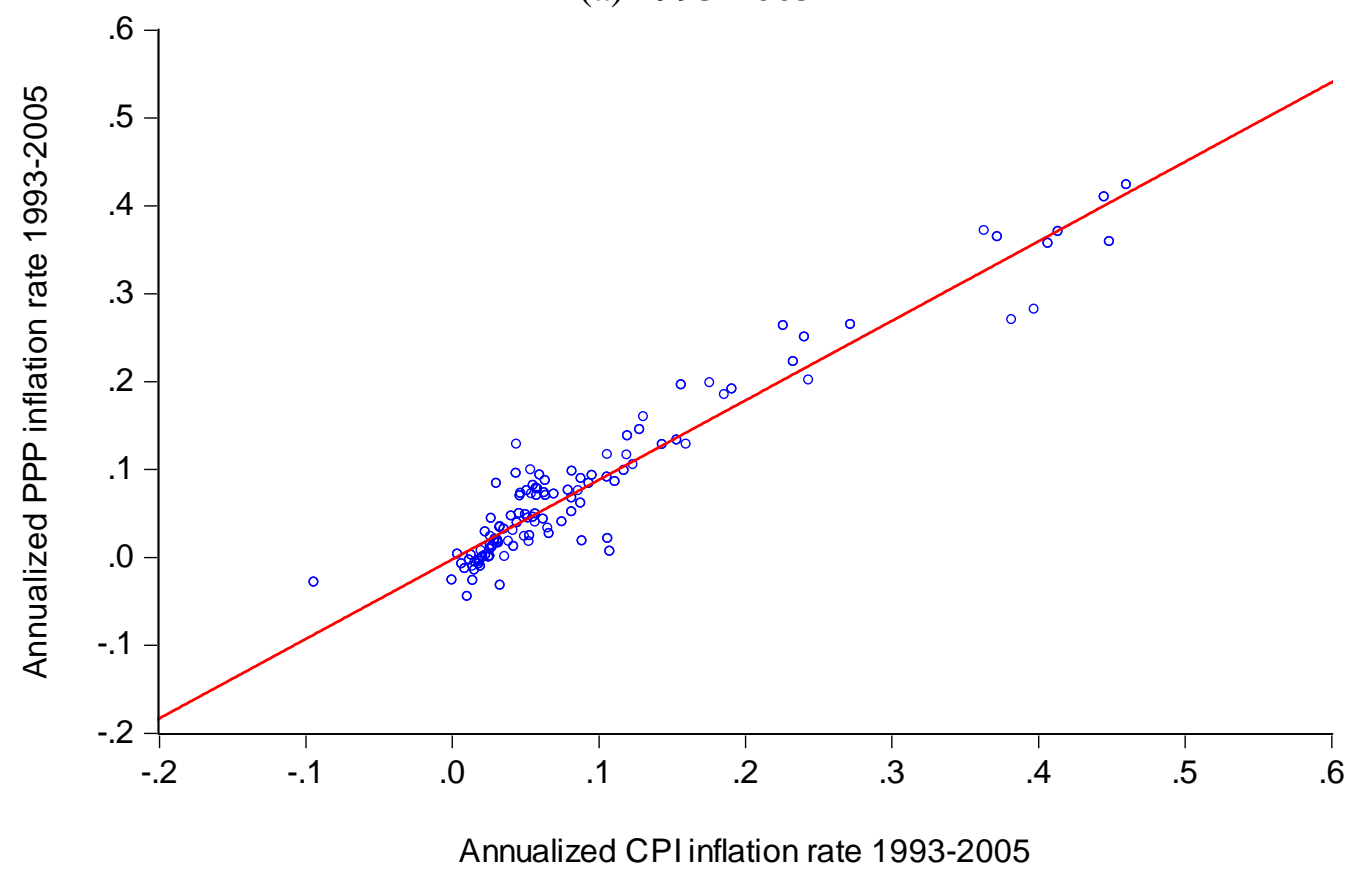

(b) 2005-2011

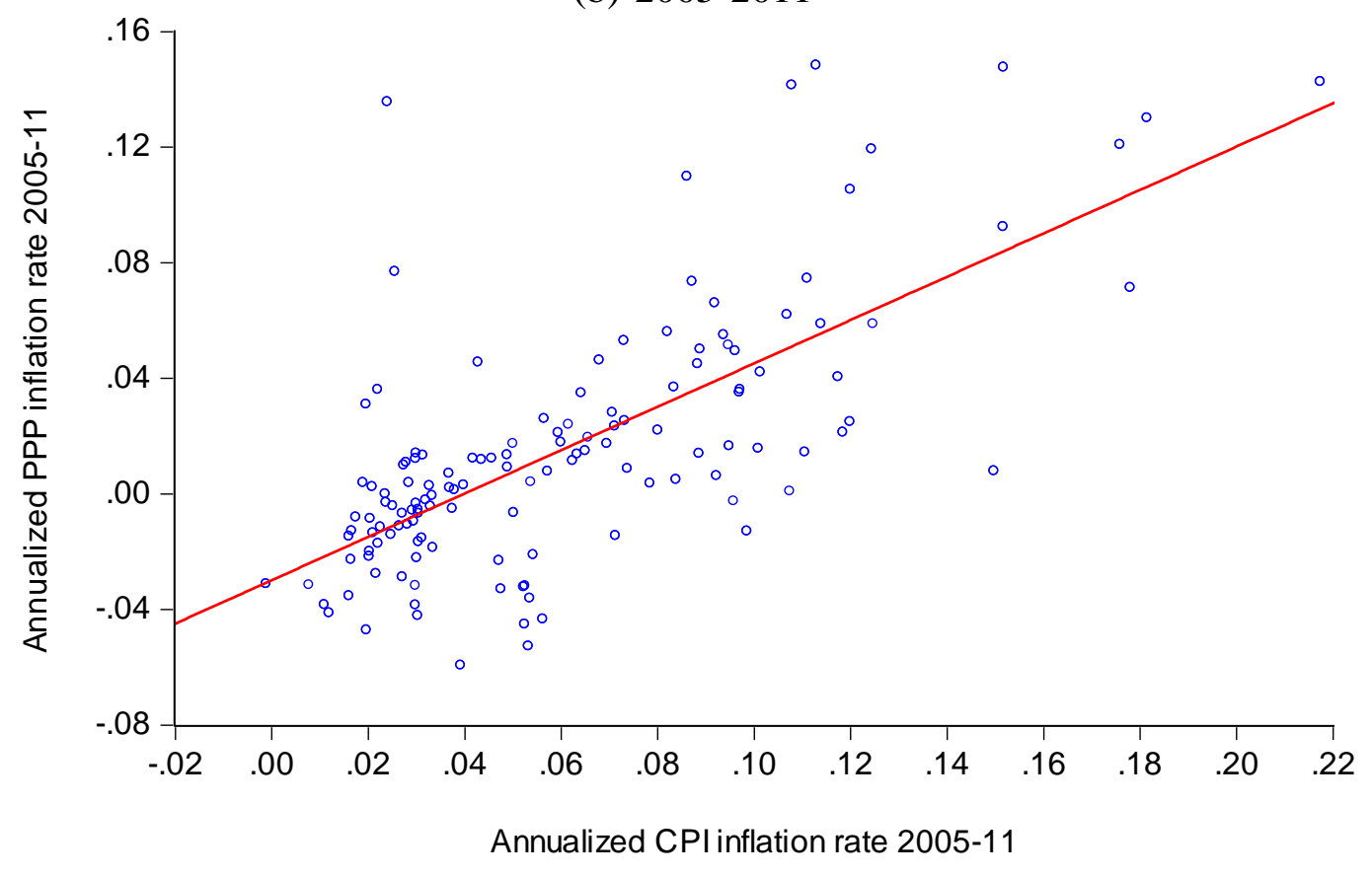


Figure 5: Histogram for annualized change in market exchange rate 2005-11

Annualized change in log MER 2005-11

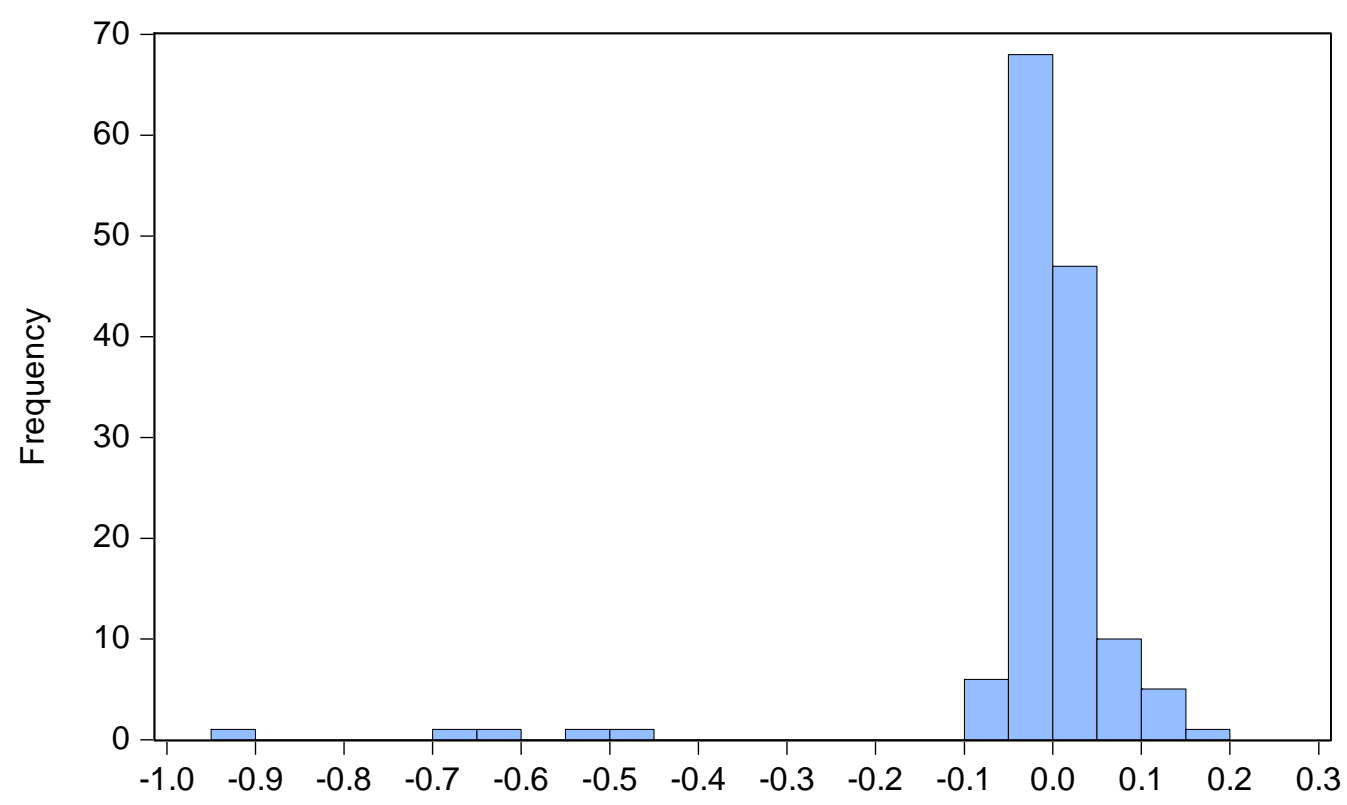


Figure 6: Plot of the residuals for a regression of annualized change in log PLI allowing for the DPE and TGP on GDP per capita in 2005

(a) All countries

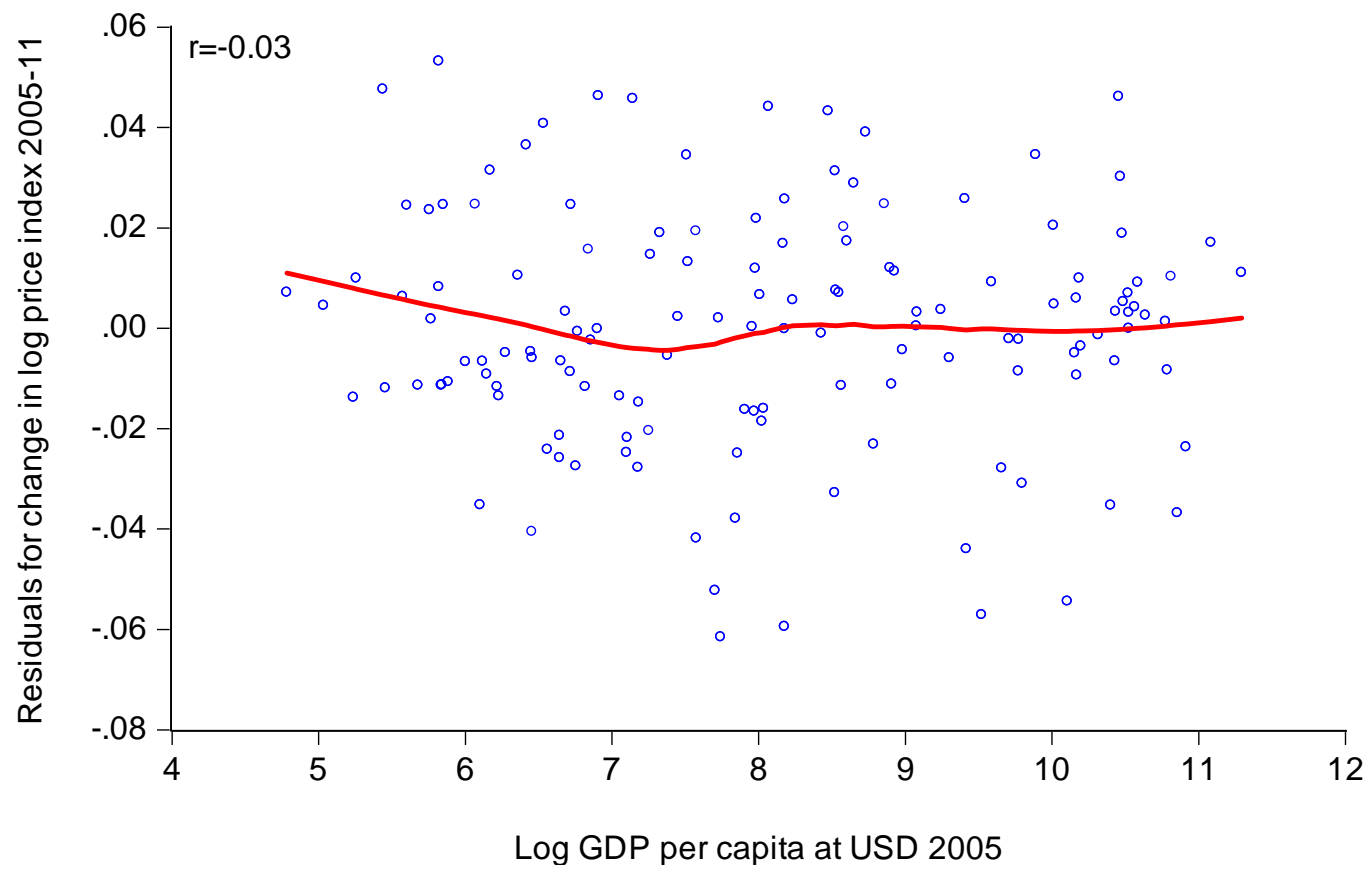

(b) Developing countries only (excluding Europe/OECD)

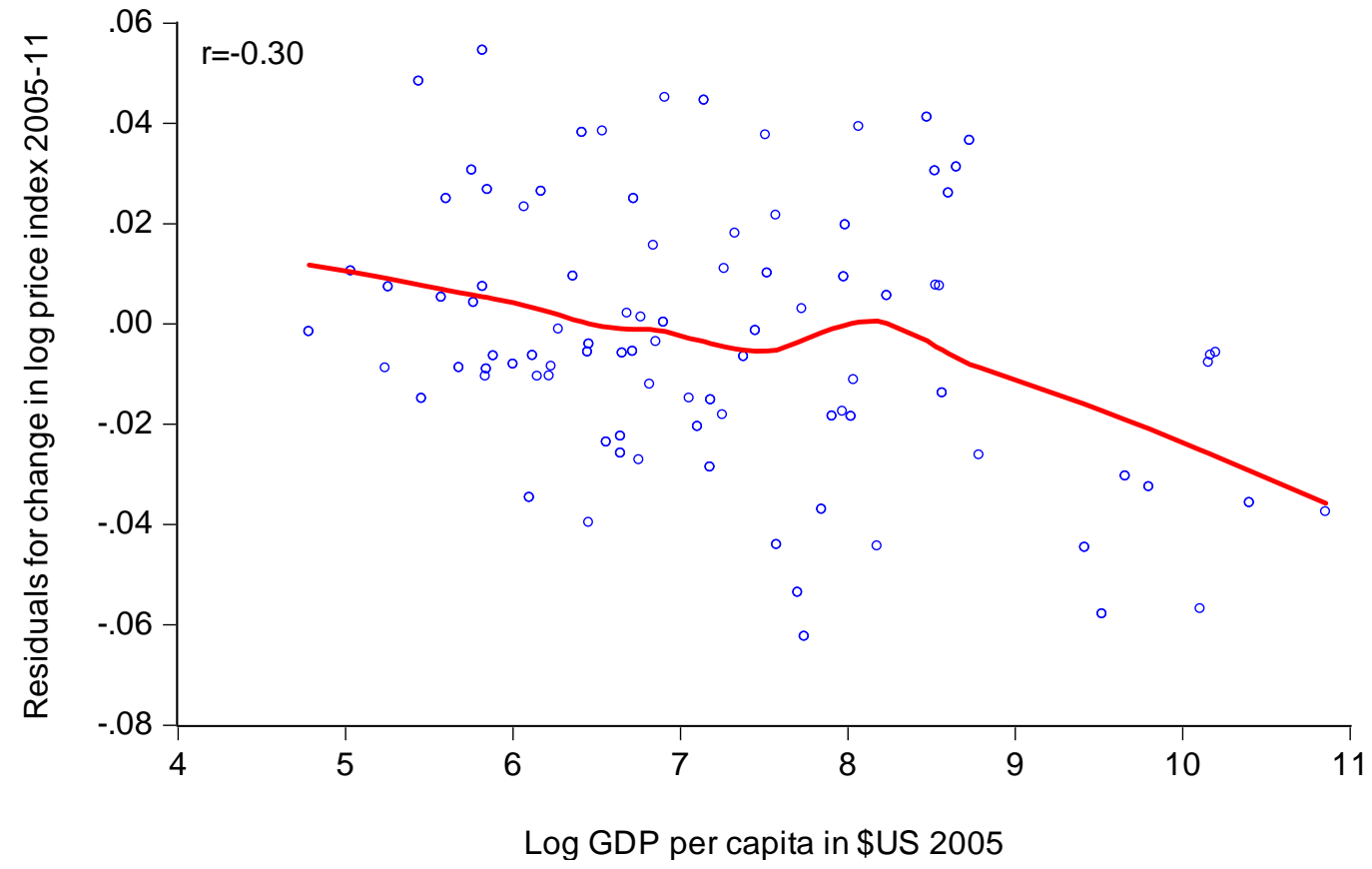

